\title{
What Affects Usage Satisfaction in Mobile Payments? Modelling User Generated Content to Develop the "Digital Service Usage Satisfaction Model"
}

\author{
Arpan Kumar Kar ${ }^{1}$ \\ Published online: 18 July 2020 \\ (C) Springer Science+Business Media, LLC, part of Springer Nature 2020
}

\begin{abstract}
Mobile payment services have become increasingly important in daily lives in India due to multiple planned and unplanned events. The objective of this study is to identify the determinants of usage satisfaction of mobile payments which could enhance service adoption. The "Digital Service Usage Satisfaction Model" has been proposed and validated by combining technology adoption and service science literature. First the data was extracted from Twitter based on hashtags and keywords. Then using sentiment mining and topic modelling the large volumes of text were analysed. Then network science was also used for identifying clusters among associated topics. Then, using content analysis methodology, a theoretical model was developed based on literature. Finally using multiple regression analysis, we validated the proposed model. The study establishes that cost, usefulness, trust, social influence, credibility, information privacy and responsiveness factors are more important to increase the usage satisfaction of mobile payments services. Also methodologically, this is an endeavour to validate a new approach which uses social media data for developing a inferential theoretical model.
\end{abstract}

Keywords Mobile payments · Digital Service Use; Service Quality · Usage satisfaction · Social Media Analytics · Big data analytics

\section{Introduction}

The use of mobile payment services has witnessed a lot of growth due to planned and unplanned interventions in India. On 8th November 2016, the Government of India announced the demonetization of all larger currency notes (Mohan and Kar 2017). Further, policy changes were announced by service providers to promote the use of mobile payments in 2017 and 2018, like discounts and cash-backs. So after demonetization, there has been tremendous focus to enhance the usage of mobile payment services in India. National initiatives in India like Digital India, also attempted to contribute to the growth of mobile payments, with initiatives like targeting very high mobile connectivity and internet penetration along with digital literacy missions for the rural households (Joseph et al. 2017; Mukherjee et al. 2019). Similarly, with the pandemic, COVID-19, which started in January 2020; globally mobile

Arpan Kumar Kar

arpankar@iitd.ac.in

1 Department of Management Studies, Indian Institute of Technology Delhi Hauz Khas, New Delhi 110016, India payment usage witnessed a significant boost as concerns were raised that cash may become a carrier for the virus, and thereby facilitate the spread of the pandemic.

The main reason for the promotion of mobile payments services is to make the citizens digitally empowered, reduce intermediation and thereby make the society cashless, paperless and faceless. Mobile payments services play a vital role in this twenty-first century, as in this digital world, the users have their own phone and through few clicks users can easily transfer money without the constraints of geographical distance between payer and payee, access to paper bills and time (Grover et al. 2017). Mobile payments is a subset of electronic payments which enables payments of good and services without any use of paper cash and payments is done by using wireless and other communication channels (Dahlberg et al. 2008). In other words, mobile payments empower individuals to make online payments for any products and services such that there is no constraints of physical proximity, geographical barriers and traceability of payments through a mobile phone with internet connectivity.

Mobile payment service providers play an important role to increase the economic growth of a country like India as they also provide or enable a host of digital services such as fund 
transfer, micro-financing, short term loans, online ticketing, online shopping and payment for utilities (Grover et al. 2017). It means that there is no need to carry paper cash while engaging in these activities of daily life. Due to the worldwide growth of the internet and the growing popularity of electronic commerce, mobile payments play an even more critical role in this economy (Yu et al. 2002). There are many efforts globally to increase the mobile payments services and to remove tangible cash in society. However acceptance of mobile payments is highly dependent upon usage experiences like other information systems (Wixom and Todd 2005). Technologies have been giving new directions not only to societies but also industries. Finance companies and technology companies have come together to different new business models for mobile payments (Puschmann 2017). These new models provide an online platform between users and merchants to engage without the physical transfer of cash, thereby crossing the challenges of access to cash, geographic barriers, economic barriers and even on credit. Mobile wallets services allow peer-to-peer transaction between merchants and users and transactions are can be done without any geographical constraints (Tankovic and Benazic 2018).

Recent review of customer experience literature also indicates that there is a lack of studies measuring customer experience immediately after digital service encounters (Becker and Jaakkola 2020). This gap may be due to the challenge for researchers whereby it becomes difficult due to the distance of the context and the researcher at the time of service encounter; when the incident that triggers any unexpected reaction. However firms can continue to measure it by sharing a close-ended survey with the customer. In this context, the prime objective of this study is to identify which factors are responsible for impacting the service encounter usage experiences during a specific service encounter of mobile payments services in India. In this context, we propose the Digital Service Usage Satisfaction Model (DSUSM), which is validated in the context of mobile payments. Usage satisfaction is different from user satisfaction and is tied to a single context in a particular instance in which a service encounter is analysed. Whereas, user satisfaction is mainly captured as the sum (or average) of overall experiences of service encounters over a period of time (Wixom and Todd 2005). A novel research methodology has also been adopted to fulfil this objective. This study is undertaken by mining the user discussions surrounding the service consumption and subsequent experiences surrounding them. This user generated context has been analysed using text mining approaches like topic modelling and sentiment mining. Then the summarized topics have been mapped to constructs of technology adoption identified from literature. The usage experiences have been modelled for the topics using sentiment mining. The relationship of the factors affecting adoption and their associated service experiences have been validated using multiple regression analysis.
In particular, our study is guided by the following research questions. The first four of which are in the domain of mobile payment service science and the last research question addresses a methodological gap in existing social media analytics driven research.

RQ1: How do users discuss about usage experiences surrounding service encounters of mobile payments?

RQ2: What are all the antecedents that impact usage satisfaction during service encounters of mobile payment across user groups?

RQ3: How are these antecedents that impact the service usage satisfaction associated with each other?

RQ4: How do these antecedents impact usage satisfaction during service encounters of mobile payments?

This rest of the study is divided into seven sections. In the second section, we provide an overview of the related literature. In the third section, we describe the research questions and hypothesis which has been used for theory building. The fourth section describes the research methodology of the study. The fifth section describes the findings of our study. The sixth section describes the implication of these results. The seventh section describes the conclusion which is derived from the study. The eighth section describes the limitation of this study and concludes with future research directions.

\section{Literature Review}

The literature review is divided into the three sections: (1) Adoption of mobile payments services; (2) Service experience discussion in social media; (3) Research gap and contribution of the current study.

\subsection{Adoption of Mobile Payments}

Literature indicates that technology plays a vital role in increasing the growth of mobile payments service in purchasing good and services. While adopting any technology facilitated service, a number of theories have been used in existing literature and adoption is one of the more popular areas in information systems discipline. Dominant theories in in the technology adoption literature are Theory of Reasoned Action (TRA), Technology Acceptance Model (TAM), Theory of Planned Behaviour (TPB), Diffusion of Innovation (DOI), Theory of Interpersonal Behaviour (TIB), Unified Theory of Acceptance and Use of Technology (UTAUT), Model of Adoption of Technology in Households (MATH) and Motivational Model. Several studies have attempted to add more constructs to explain adoption behaviour better over the years. An overview of the fundamental theories and their constructs are illustrated in Table 1. 
Table 1 Adoption Theories used in Information System Literature

\begin{tabular}{|c|c|c|c|}
\hline $\mathrm{SN}$ & Theories & Dominant factors & Reference Study \\
\hline 1 & Theory of Reasoned Action (TRA) & $\begin{array}{l}\text { Customer-attitude, social influence, and } \\
\text { behaviour. }\end{array}$ & Aizen and Fishbein 1977 \\
\hline 2 & Technology Acceptance Model (TAM 1, 2, 3) & $\begin{array}{l}\text { TAM 1-Percieved usefulness, ease of use, in- } \\
\text { tention to use, usage behaviour. } \\
\text { TAM 2-Subjective norm, image, job } \\
\text { relevance, output quality, result } \\
\text { demonstrability, experience, voluntariness } \\
\text { TAM 3-Individual differences, system } \\
\text { characteristics, social influence, and facili- } \\
\text { tating conditions }\end{array}$ & $\begin{array}{l}\text { Davis } 1989 . \\
\text { Venkatesh and Davis } 2000 . \\
\text { Venkatesh and Bala } 2008\end{array}$ \\
\hline 3 & Theory of Planned Behaviour (TPB) & $\begin{array}{l}\text { Behavioural control, subjective norm, and } \\
\text { behavioural attitude }\end{array}$ & Ajzen 1991. \\
\hline 4 & Diffusion of Innovation (DOI) & $\begin{array}{l}\text { Adoption characteristics, innovation } \\
\text { characteristics and innovation-decision } \\
\text { process }\end{array}$ & Rogers 1995. \\
\hline 6 & $\begin{array}{l}\text { Model of Adoption of Technology } \\
\text { in Households (MATH) }\end{array}$ & $\begin{array}{l}\text { Attitudinal Beliefs, Normative Beliefs, } \\
\text { Control Beliefs. }\end{array}$ & Brown and Venkatesh 2005 \\
\hline 7 & $\begin{array}{l}\text { Unified Theory of Acceptance and } \\
\text { Use of Technology (UTAUT) }\end{array}$ & $\begin{array}{l}\text { UTAUT Effort expectancy, performance } \\
\text { expectancy, social influence, and } \\
\text { facilitating conditions. } \\
\text { UTAUT2: hedonic motivation and price } \\
\text { value }\end{array}$ & $\begin{array}{l}\text { Venkatesh et al. } 2003 \\
\text { Venkatesh et al. } 2012 .\end{array}$ \\
\hline 8 & Motivational Model & Extrinsic Motivation, Intrinsic Motivation. & Venkatesh and Speier 1999. \\
\hline
\end{tabular}

Adoption literature focused on electronic payments indicates that significant effects towards use are derived out of the ease of use, perceived quality of such services and satisfaction over a period of continued usage (Jun and Cai 2001; Rana et al. 2013; Slade et al. 2015; Teoh et al. 2013). These studies indicate that to promote electronic payments, it would be necessary to explore the frameworks which assess the quality of such digital services. Further adoption of electronic payment services depends upon the country environment, culture, technology and government (Berthon et al. 2012). Reviews of literature on the consumption of mobile application services identified factors such as perceived quality, usefulness, social-influence, flexibility have played a powerful role in increasing its adoption rate (Chhonker et al. 2017). Reviews on extended theories of adoption literature indicate a plethora of additional constructs along with these main constructs as indicated in Table 1 are available, like perceived trust, perceived security, price value, performance expectancy, to name a few (Slade et al. 2013; Rana et al. 2017; Chhonker et al. 2017, 2018; Dwivedi et al. 2019; Tamilmani et al. 2020). Adoption literature on mobile payments also highlight the relevance of theories on user resistance to such changes due opportunity appraisal factors like perceived value, threat appraisal factors like consequences of using new systems and secondary appraisal factors like sense of control while using such platforms (Gong et al. 2020).

These theories on adoption are sometimes explored using service science theories, like SERVQUAL and WEBQUAL, using factors like responsiveness, tangibility, reliability, assurance, empathy (Parasuraman et al. 1988). These models are widely used to measure the perception of customer towards the service quality: a gap between services the customer expected to receive and what they have been received, even in technology enabled services (Parasuraman et al. 1988; Loiacono et al. 2007). Further literature (Dahlberg et al. 2008; Zhou 2011) highlights the importance of factors like risk, security, usefulness, socialinfluence, information-privacy, trust, usefulness also important service quality factors. These frameworks like SERVQUAL and WEBQUAL very useful to evaluate the customer expectations and their perception towards firms in terms of their service delivery (Loiacono et al. 2007). Further, reviews of literature (Chhonker et al. 2018; Southard and Siau 2004; Hong and Tam 2006) identified that factors like assurance, confidentiality, usefulness, trust, security, customer attitude, credibility, reliability, ease of use, cost, tangibility, performance, responsiveness, social influence, and information-risk which could affect the perceived quality of services significantly based on a single service encounter and thus impact the adoption of digital services like electronic payments. Overview of these factors are illustrated in Table 2. Literature indicates that there are many other factors, but we have briefly described 15 factors which have been identified as being relevant in our study, through the process of looking at the data obtained from summarization of texts of user generated content.

\subsection{Service Consumption Discussion in Social Media}

In this digital world, seventy percent of customers used social media sites to access information, forty-nine per cent of 
Table 2 Factors affecting mobile payment service encounters and usage experience

\begin{tabular}{|c|c|c|c|}
\hline $\mathrm{SN}$ & Dimensions & Explanation & Literature Evidence \\
\hline 1 & Cost (price) & Fees paid per transaction or one time for onboarding & $\begin{array}{l}\text { (Shon and Swatman 1998) } \\
\text { (Kapoor et al. 2014) }\end{array}$ \\
\hline 2 & Usefulness & $\begin{array}{l}\text { Transaction requirements, Finance related issues of } \\
\text { customers should be satisfied. }\end{array}$ & (Pachpande and Kamble 2018) \\
\hline 3 & Ease of use & $\begin{array}{l}\text { The ease with which a digital transaction may be } \\
\text { undertaken by the user }\end{array}$ & $\begin{array}{l}\text { (Guriting and Oly Ndubisi 2006; } \\
\text { Rana et al. 2013). }\end{array}$ \\
\hline 4 & Trust & $\begin{array}{l}\text { Trust on the individual, system or organization facilitating } \\
\text { the service delivery }\end{array}$ & Slade et al. 2014) \\
\hline 5 & Performance & $\begin{array}{l}\text { Performance of regularity of desired outcome of the digital } \\
\text { transaction }\end{array}$ & $\begin{array}{r}\text { (Venkatesh et al. 2006; } \\
\text { Gholami et al. 2010) }\end{array}$ \\
\hline 6 & Security & $\begin{array}{l}\text { Maintaining confidentiality, authenticity, } \\
\text { non-repudiability between users and services. }\end{array}$ & (Papa et al. 2010) \\
\hline 7 & Social Influence & $\begin{array}{l}\text { Views of support or prestige associated among social } \\
\text { groups and peers when a service is used }\end{array}$ & (Koenig-Lewis et al. 2015) \\
\hline 8 & Information Risk & $\begin{array}{l}\text { The risk of information getting affected, accessed or } \\
\text { misused when information interchange happens } \\
\text { in a transaction }\end{array}$ & (Slade et al. 2015; Leong et al. 2003). \\
\hline 9 & Credibility & $\begin{array}{l}\text { The extent that a user's trusts the promises of service } \\
\text { delivery by the firm. }\end{array}$ & (Parasuraman et al. 1988) \\
\hline 10 & Assurance & $\begin{array}{l}\text { Ability to convey confidence that the service provider will } \\
\text { act in the interest of the user and deliver what it was } \\
\text { supposed to do. }\end{array}$ & (Parasuraman et al. 1991) \\
\hline 11 & $\begin{array}{l}\text { Customer Support } \\
\text { (Attitude) }\end{array}$ & $\begin{array}{l}\text { The orientation of the service provider to support the } \\
\text { customer's needs for issues related to service } \\
\text { consumption }\end{array}$ & (Arvidsson 2014) \\
\hline 12 & Responsiveness & $\begin{array}{l}\text { How quick is the service provider to address issues when a } \\
\text { service request is raised by a user? }\end{array}$ & $(\operatorname{Lin} 2013)$ \\
\hline 13 & Confidentiality & $\begin{array}{l}\text { Information should be restricted among the parties } \\
\text { involved in the transaction. }\end{array}$ & (Meharia 2012) \\
\hline 14 & Information Privacy & $\begin{array}{l}\text { The personal and sensitive information collected during a } \\
\text { transaction will not be shared or used beyond intended } \\
\text { usage or user groups }\end{array}$ & (Tsai et al. 2011) \\
\hline 15 & Reliability & $\begin{array}{l}\text { The systems will continue to provide uniform quality of } \\
\text { services outcome over time. }\end{array}$ & (Parasuraman et al. 1988) \\
\hline
\end{tabular}

customers use social media sites for taking any purchase decision based on information present in the social media sites, sixty per cent users use social media sites only to share their views with others; forty-five per cent users use social media sites only for word-of-mouth (Kim and Ko 2012 ; Tan and Lee 2019). Electronic word of mouth related to service encounters and access to internet impact intention to use a technology enabled service (Chaudrie and Dwivedi 2005; Ismagilova et al. 2019). Social media platforms like Facebook and Twitter play an important role in this digital world for sharing information, to maintain public relation, and to exchange opinion among users (Grover et al. 2017). Social media sites are platforms in which social or professional friends interact with each other for sharing their ideas or opinions (Trusov et al. 2009).In this digital world, all users using social media sites for marketing (Thackeray et al. 2008), for the promotion of their product and services (Neiger et al. 2012), for increasing job opportunities (Henderson et al. 2013), governments organizations use social media sites as a communication channel for the public (Kim and Ko 2012; Chang and Wang 2011). Various industries use social media sites for the marketing of their products and services such as retailing, tourism, news, entertainments industry (Grover et al. 2017). Marketing is done in social media sites for any products and services with less effort and cost, it also maintains the strong relationship with their customer and increases the profits of the industries (Kim and Ko 2012). Firms also engages with customers in social media in a number of ways. First is in the traditional form in which there is a direct communication between customers and the organization through paid promotion. The second form is social communication in which users communicate with other users then they discuss the user experiences about the product and services delivers by any organizations and industries (Paniagua and Sapena 2014; Mangold and Faulds 2009). Communication between firms and customers over social media is not only cost effective, but also helps in building brand engagement and strengthens customer relationships (Zheng et al. 2015). Social media is one of the 
dominant platforms for users in which they can resolve their queries related to new technologies, products and services (Kapoor et al. 2018; Rathore and Ilavarasan 2020). Users frequently attempt to interact and engage with firms based on their service encounters and share their inputs for improving quality of services (Howard et al. 2014; Rathore and Ilavarasan 2020).

\section{Theory Development}

Our review of literature on digital service science in general and mobile payments in particular reveal the following overview and gaps which we attempted to address:

- Studies have attempted to find antecedents to technology adoption a lot in existing literature but the connect with usage experience is missing.

- Studies have focused on service delivery process and service quality as an outcome extensively in service science literature.

- Studies indicate that service quality literature is also connected to adoption and establishes that good perceptions surrounding service quality facilitates adoption.

- However there is no study to measure digital service usage experience by connecting these two bodies of literature, especially by mining user generated content.

- Further there is no attempt to establish antecedents of service usage experience in existing digital service usage behaviour, as researchers are distanced from the customer at the time of service encounter.

Usage experience at the point of service consumption is difficult to capture by researchers who are external to the encounter. The current study is a major leap in this direction to combine approaches of social media analytics with inferential analysis to develop such a large integrative perspective by proposing the DSUSM model. This requires us to explore the first two research questions which are predominantly exploratory in nature. Our first research question attempts to explore whether users share their usage experience on digital service consumption, and if they do, what kind of polarity are typically highlighted in such social media discussions. This enables us to measure sentiments of the core tweets which will later be used to measure usage satisfaction as a dependent variable.

Twitter is one of the popular microblogging platforms and has the potential for capturing mutual intelligence from large numbers of users (Grover et al. 2019a). Also by this approach, a complex theoretical model may be developed which otherwise is not feasible to validate through survey based methods, since the survey instrument would be too long to collect responses without creating any stress or biases among respondents. We developed our hypotheses with the theoretical models extended from different technology adoption and service quality models and further added certain constructs to extend the already existing theories surrounding adoption. We begin by discussing fifteen hypotheses that were related to the mobile payment's services. The dependent variable is usage satisfaction (extended from Venkatesh et al. 2003; Lin and Sun 2009), defined as the individual probability towards the use of technology. In this study, the polarity of a user's sentiment in a context of user generated content, has been used as a proxy for usage satisfaction. If an user is satisfied, the assumption is that the polarity of the tweet will have a positive sentiment. Similarly, if the user is not satisfied from a service encounter, the assumption is his tweet will have a negative polarity in terms of sentiment.

Further it was necessary to identify antecedents which would affect this usage satisfaction. For this, we had to adopt an inductive research methodology whereby revisit the data carefully and identify factors from the summarization of social media discussions. This exploratory study is undertaken to address the second research question whereby we attempted to address the second research question by connecting the outcome of text summarization with the understanding of literature based on reviews. Based on text summarization methods, fifteen factors could be identified from existing literature. The methodology of identifying these factors is elaborated in the research methodology. These independent variables were cost (Shon and Swatman 1998), usefulness (Davis et al. 1989; Karnouskos 2004), trust (Yousafzai et al. 2003), information-risk (Slade et al. 2015), security, social influence (Koenig-Lewis et al. 2015), ease of use (Venkatesh et al. 1996), performance (Venkatesh et al. 2006), credibility (Wang et al. 2003), reliability (Zhu et al. 2002), informationprivacy (Leong et al. 2003), responsiveness (Lin 2013), Customer-attitude (Davis et al. 1989), confidentiality (Meharia 2012), and assurance (Wang et al. 2003), as illustrated in Fig. 1. In subsequent part of this theory development section, we attempt to address the third and fourth research question for developing the theoretical model for validation.

Usage Satisfaction Customer perception and satisfaction surrounding a service encounter play a vital role for getting the success of any new technology, therefore mobile payments services get adopted only when customers have positive perception and usage satisfaction towards mobile payments services (Oliver 1994; Sun et al. 2009). Literature indicates that adoption of online transaction is highly governed by customer satisfaction and their choices of method of transaction (Dahlberg et al. 2008). However customer or user satisfaction typically emerges over multiple service encounters whereas usage satisfaction is generated at the context of service encounter (Wixom and Todd 2005). Such a measure for customer satisfaction would be typically captured as the sum or average of different usage satisfaction out of numerous service encounters. Typically, most of the past literature measures 
Fig. 1 A holistic framework for the assessment of usage satisfaction of mobile payments

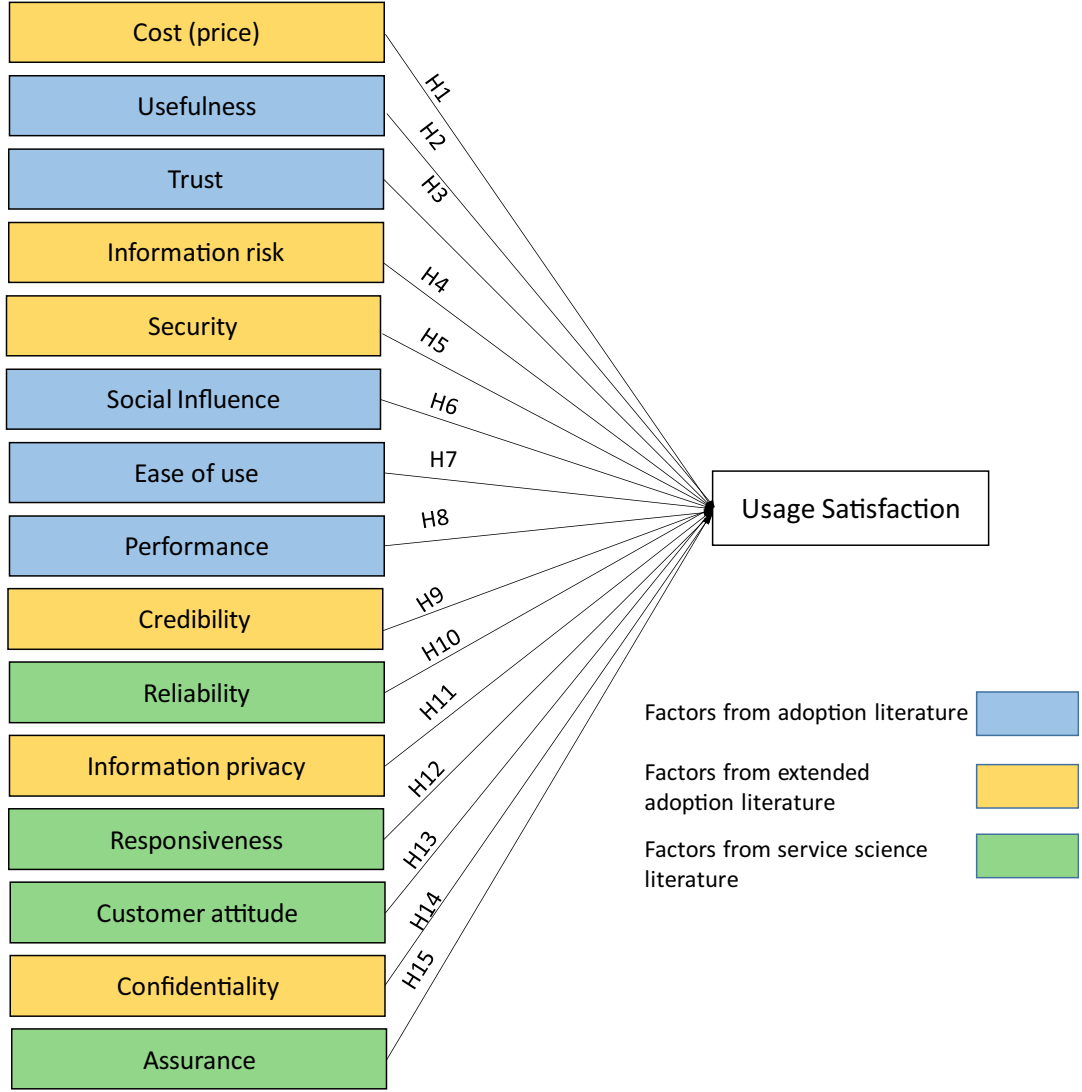

overall customer satisfaction since measuring usage satisfaction is difficult due to access to the customer at the moment of service consumption. However firms typically ask users to rate their service encounters after a service is consumed as it helps in service improvements and can create positive or negative user generated content which is a better measure for usage satisfaction. However getting access to individual such ratings after service consumption may be challenging unless we use the user generated content surrounding this service encounter. Recent reviews of literature also highlight that measuring customer experience at the point of service encounters becomes difficult during digital service usage by customers (Becker and Jaakkola 2020). However this user generated content or electronic word of mouth may affect future use of the service (Ismagilova et al. 2019). In this study, a customer's usage satisfaction from the mobile payment service encounter has been captured through a proxy of the sentiment of a topic which is identified through text summarization in user-generated content. The topic represents the usage context and associated words relevant to the context which multiple customers may have shared while sharing their experience regarding a service encounter. Usage satisfaction is the dependent variable in our study which is captured using sentiment mining methods derived from social media analytics by analysing the polarity of the topic.
Cost (price) This factor captures the cost of using mobile payments services while engaging in a transaction. Cost of onboarding into a system or for completing a transaction should be lower for increasing the acceptance rate of digital services (Mallat 2007; Liang and Huang 1998). Literature indicates that higher cost per transaction, communication cost and subscription cost often affect the consumption of digital services in both individual and organizational setting (Shafinah et al. 2013; Chatterjee and Kar 2020). There are evidences in UTAUT2 that price has a significant impact on behavioural intention. Hence extending this argument, we felt that cost would also impact usage satisfaction, if this cost was associated with every usage (like cost per transaction). Therefore we hypothesise $\mathrm{H} 1$ as follows.

$\mathrm{H1}$ : There is a negative relationship between cost and usage satisfaction

Usefulness Digital payment models facilitates the user to withdraw their money anywhere at any time with very minimal charges (Omwansa 2009). It posits that a technology driven platform should have tangible benefits which would promote their adoption as well (Davis 1989). If the users percieve that mobile payments are more useful, as compared to other modes of payments, they should have a positive impact on usage satisfaction. Therefore we propose $\mathrm{H} 2$ as follows. 
$\mathrm{H} 2$ : There is a positive relationship between usefulness. and usage satisfaction.

Trust Trust is basically used to identify how much risk associated while doing any financial transactions i.e. trust is directly proportional to usage satisfaction, if trust increases then the perception of users towards mobile payments automatically increases. Trust helps to maintain the transactional relationship between merchant and customers (Peha and Khamitov 2004). Trust plays an important factor in the adoption of mobile services because the online transaction, besides being intangible, a significant degree of perceived risk and unpredictability is involved (Slade et al. 2014; Salo and Karjaluoto 2007; Arif and Du 2019). Antecedents of trust are factors like talent, kindness and honesty (Kassim and Abdullah 2010; Sebastianelli and Tamimi 2018). Talents mean that the service providers have knowledge and experience to deliver the desired services. Honesty means that the service provider is not perceived to cheat users and will satisfy the commitments. Kindness indicate that the service providers are expected to satisfy the requirements of their users positively. Literature indicates that trust helps to build preference towards the adoption of a digital service and having higher trust on a system should also lead to higher usage satisfaction. Hence we hypothesize H3 as follows.

H3: There is a positive relationship between trust and usage satisfaction

Information Risk Information risk plays an important factor in increasing the usage of digital services (Mustafa et al. 2020). Digital payments services are required to maintain the integrity and authorization of transactions (Slade et al. 2015). Reduced information risk instils higher user confidence because users lower their apprehension of losing their personal information and financial information to external entities intentionally or accidentally (Leong et al. 2003). Information risk factors could be triggered by economical, performance, social, time or financial triggers (Shon and Swatman 1998; Mustafa et al. 2020). If the information risk increases, as perceived by the consumer, there is a greater chance that the consumer may not adopt or use the technology (Leong et al. 2003; Slade et al. 2015; Weerakkody et al. 2017). Therefore we extend that argument that perceived information risk should have an adverse impact on the usage satisfaction of a digital service. As illustrated in Fig. 1, we propose H4 as follows.

H4: There is a negative relationship between information risk and usage satisfaction

Security In this digital world, security plays a very important factor to maintain the relationship between merchant, users and with payments system (Siau et al. 2004; Mallat 2007).
Security is one of the major concerns for customers. In mobile payments, users have their own private key or secret code for the online transaction it developed perceived security in mobile payments transactions. In these digital environments, it required to maintain mechanisms of authentication, authorization, non-repudiation between users, merchants and payments services (Shon and Swatman 1998). Perceptions surrounding security is often identified as one of the biggest challenges for all the users of digital services and smart technology products as they capture a lot of data and so digital identity systems are sometimes used to enable better security for such platforms (Stadler 1999; Mir et al. 2019). If users have concerns surrounding how others may access and use the information that is shared in a digital service, they tend to use it lesser (Weerakkody et al. 2017). We extend this argument that typically such user may be more dissatisfied from such service encounter. As illustrated in Fig. 1, we propose H5 as follows. H5: There is a positive relationship between security and usage satisfaction

Social influence Social influence play a tremendous role while increasing the rate of adoption of consumer focused digital services including mobile based services (Venkatesh et al. 2003; Shin 2009). Social groups can enable users create a perceived support system for trying new technologies, if the confidence of using the new technology is less. For mobile payment, social influence plays a dominant role in impacting intention to use and subsequently adoption (Slade et al. 2014). It can become even more critical, if there is a sudden intervention. Interventions in India like demonetization also encouraged users to use mobile payments services for transactions suddenly. Because of the sudden nature of such interventions, we hypothesized social influence to be a critical factor. Further, even if one starts using such a service, we perceived it would also impact the experience associated with such usage, if there were support from social groups. Greater the support while individuals were using it, better is the service usage experience.

H6: There is a positive relationship between social influence and usage satisfaction

Ease of use For any digital service, adoption is often impacted by ease of use of the service, as has been illustrated in adoption literature like TAM. Mobile payments services are easy to use therefore it should provide a positive attitude to usage satisfaction (Guriting and Oly Ndubisi 2006). If mobile payments service is easy to use then it will remove any kind of transaction errors and it is one of the important aspects of any online financial transactions (Flavian et al. 2006). Literature indicates that despite the progress of different adoption literature, Ease of Use from TAM remains one of the critical factors 
which drives technology usage (Rana et al. 2013). Extending this argument that users who use a technology are likely to be having greater usage satisfaction, if the platform is easier to use as compared to other platform. Therefore we propose H7 as follows.

H7: There is a positive relationship between ease of use and usage satisfaction

Performance Performance is basically used to measure how customers feel after the use of mobile payments services, it helps to perform the transaction online anywhere and at any time, it also measures the risk, speed, authentication while performing an on-line transaction (Venkatesh et al. 2003; Gholami et al. 2010). Evidences on mobile payment adoption highlight that higher is the performance expectancy, greater is the behavioural intention to use the service (Slade et al. 2014). Extending the argument to usage satisfaction, we felt from the inductive research that performance is a key factor which affects usage satisfaction. Higher performance of the mobile application in terms of speed, authentication and network usage could have a positive impact in terms of customer's usage satisfaction. Similarly factors like crashing while running, bugs in the application could have adverse impacts on the usage satisfaction. Thus we propose $\mathrm{H} 8$ as follows.

H8: There is a positive relationship between performance and usage satisfaction

Credibility Credibility of a service provider comes out of trust on the service provider that the organization will not attempt to do anything that will harm the interest of the different stakeholders. This is driven by the trust on the service provider. The trust that an individual may have on the service provider has positive impacts on the usage intention of a digital service (Slade et al. 2015). It also defines a behavioural intention to use an information system like mobile payments services (Amin 2008). Extending the argument based on inductive evidences, we hypothesized that if the service provider has greater credibility, the usage satisfaction would be higher for a digital service like mobile payments (Kapoor et al. 2014). As illustrated in Fig. 1, we propose $\mathrm{H} 9$ as follows.

H9: There is a positive relationship between credibility and usage satisfaction

Reliability Reliability of services ensure that there is uniformity of expectations of the customer about the outcome of any service (Parasuraman et al. 1988). It also determines that a firm has the potential of delivering the promised services dependably, repeatedly over a period of time. As users indulge in repeated usage of a technology enabled service through a mobile application, the ability of the application to demonstrate the same quality of outcome, through the exchange of financial payment between intended parties, becomes critical in establishing higher reliability. Higher reliability enhances positive affect surrounding the service. As illustrated in Fig. 1, we propose the following hypothesis.

H10: There is a positive relationship between reliability and usage satisfaction

Information privacy In digital services like mobile payments, collection and sharing of unauthorised information can have a significant impact on the perceived efficacy of the service (Tsai et al. 2011; Stewart and Segars 2002). Such concerns surrounding information privacy entails the access of information residing in the system which is meant to be accessed by the mobile payment application. Information privacy is related to access rights granted to the mobile application to access data in the mobile device like location data, messages, files on the memory, usage data and network usage data (Albashrawi and Motiwalla 2019). Such privacy concerns could be related to access and use of sensitive personal information within or outside the boundary of the firm for unintended usage. If information privacy is protected, customers should be more satisfied about their service encounters. Thus as illustrated in Fig. 1, we propose H11 as follows.

H11: There is a positive relationship between information privacy and usage satisfaction

Responsiveness Mobile payment users believed that when payments or transactions are done electronically, it responds faster to their need than any other traditional methods used for payments (Lin 2013). The same is expected in terms of resolution to problems encountered during a service experience. Responsiveness may also influence the satisfaction of customer based on any online business transaction. Higher the responsiveness of the system to the inputs provided by the user, lesser is the user's time and effort which is utilised to meet the objectives and more is likely to be his satisfaction from the service encounter. Responsiveness also comes into play if an automated transaction does not fulfil intended consequences and required human intervention due to technical or process related problems. A quicker human intervention in such problems was perceived to impact usage satisfaction positively. As illustrated in Fig. 1, we propose $\mathrm{H} 12$ as follows.

H12: There is a positive relationship between responsiveness and usage satisfaction

Customer attitude Literature on customer attitudes indicate that users have a positive or negative intention to use a specific digital service which may also impact their service experience (Arvidsson 2014). Literature indicates that for internet-based 
technologies, customer attitude has a dominant role to play in its adoption (Dwivedi et al. 2007). Attitude towards a service can be due to different reasons. For example, if the cost of these payment services is low, if it became ease to use, if it provides high security and privacy but the low risk then the only customer has a positive attitude towards these payments services (Arvidsson 2014). Users attitude towards using any specific information technology and application are the important factors for determining whether individual use that system or not (Yang 2005). As illustrated in Fig. 1, we propose H13 as follows.

H13: There is a positive relationship between customer attitude and usage satisfaction

Confidentiality Confidentiality is defined as the preservation of information within intended usage and among intended stakeholders related at the time of transaction such an identity of users/merchant, credit card information or purchase of products or services (Meharia 2012). Confidentiality inherently means that the information should be secured among the parties involved in the transaction (Meharia 2012). The intended usage of a payment application is to facilitate transactions between two interested parties. However the application may have multiple other access rights in the system. How the information is collected through these access rights and regarding the transaction information, and how subsequently such information may be analysed and shared with unintended parties governs the confidentiality of data usage. Evidences in data and literature highlighted concerns surrounding how government may be monitoring transactions in mobile payments after demonetization for the purpose of taxation and governance (Mohan and Kar 2017). If concerns surrounding confidentiality were high, we envisioned an adverse impact on usage satisfaction. As illustrated in Fig. 1, we propose H14 as follows.

H14: There is a positive relationship between confidentiality and usage satisfaction

Assurance Assurance adequately increases the user's trust and decrease the risk while achieving any online transaction (Parasuraman et al. 1991). Higher assurance in an intangible service would indicate that the service consumption is communicated to the stakeholders involved effectively, thereby enhancing positive affects about the service encounter. A major concern highlighted in the data for new users that users involved in digital payments did not get a confirmation before the transaction is completed that the payment is being transferred to the right recipient (Mohan and Kar 2017). If assurance is low, usage satisfaction was also adversely impacted. As illustrated in Fig. 1, we propose H15 as follows:

H15: There is a positive relationship between assurance and usage satisfaction
The entire theoretical model has been illustrated in Fig. 1 subsequently in this manuscript. Colour coding has been done to demarcate the foundation literature though which the individual constructs are derived in this study.

\section{Research Methodology}

In this research, a mixed research methodology approach; combining both qualitative and quantitative methods; is used for analysing and measuring the factors that are derived in the Indian context. Mix research designs have better reliability while dealing with user generated content (Oh et al. 2015; Karami et al. 2020). The first phase of the study draws insights from social media analytics where algorithms can transform user generated content using approaches of descriptive analytics, content analytics and network analytics (Rathore et al. 2017; Grover et al. 2018; Grover and Kar 2020). This output is transformed through a qualitative content analysis method in the second phase of data analysis. Then in the third phase, the output of the second phase is analysed using inferential statistics like multiple regression analysis. Across these stages, the research methodology combines text analysis using sentiment mining and topic modelling with content analysis methods of social science research, and then multivariate analysis using multiple regression analysis. These approaches of combining social media analytics and statistical validation of hypothesis have shown immense potential in recent times, but multi-variate analysis has not been attempted to explain a theoretical perspective on a domain. We attempt to follow the guidelines highlighted by Berente et al. (2019) in their commentary towards building theory in information systems based on data driven approaches.

\subsection{Data Collection}

For this study, data was collected from Twitter by using Python for over a period of 9 months from October 2018 till June 2019, by using the popular hashtags (top 5) and @ mention used for mobile payments services. These service provider are identified as the top 8 mobile payment service provider based on data listed by the government of India in NPCI website. Other service providers had specifically local coverage and did not have presence beyond three states. Discussions on Twitter surrounding mobile payment service providers of such as Paytm, MobiKwik, Freecharge, Oxygen Wallet, NPCI_BHIM, PayUMoney, PhonePe, Razorpay were extracted. When the official account of these service providers have been mentioned (@mentions), the data has been collected using the Twitter API. Using this API, at a particular point of time, Twitter allows 5\% of the discussions surrounding the searched keyword to be extracted. Among these service providers, NPCI_BHIM is a public service provider while the rest are private firms. 
Fig. 2 Approach for theory building using social media analytics

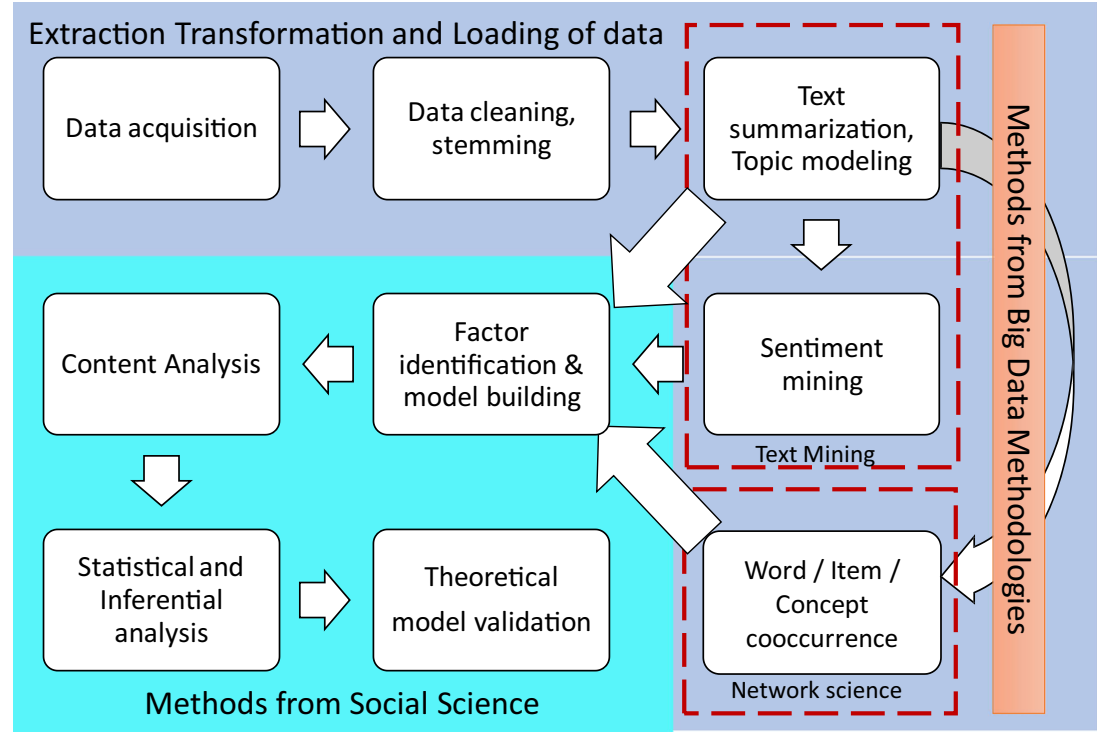

While the original extracted tweets exceeded eight lakhs, a total of 400,242 tweets were identified after the cleaning process. Literature highlights that many studies have been conducted with sample sizes of even a lakh tweets are sufficient for theory development based on user generated content (Grover et al. 2019a, b, c; Aswani et al. 2018). In the cleaning process, the retweets and tweets which were not in English were removed as this would have been difficult for our analysis based on existing capabilities of natural language processing. Further tweets which had only links or images and were having text less than five words were also removed in this tweet extraction process as they do not have significant information surrounding the usage experience which can be used for further analysis. Further all tweets were removed which did not originate from an user where the user profile did not have an image and was less than 30 days old, so as to ensure the profile is genuinely representing an user.

The extracted data was cleaned to remove stop words, meaningless characters such as HTML tags, punctuation, numbers, emoticons are removed through stemming.
Stemming is a process where derivations of words are reduced and mapped to the base word so that uniformity of analysis can be achieved. By undertaking stemming, one attempts to reduce the inflectional variations of each word which may have been introduced by a very large number of users to a common base or root. Typically when many users discuss about a theme, they tend to use different variation of the same word and these words needs to be mapped to the base stem word for better accuracy of analysis (Grover et al. 2019b). It operates by truncating the prefix or suffix of the word found in large volumes of text, and map the core word to an existing dictionary. The entire process of cleaning the tweets and stemming was undertaken by using the Python NLTK package where a database of English dictionary is available for Natural Language Processing.

\subsection{Data Analysis Methodology}

The tweets were analysed subsequently using topic modelling for tweet summarization. Topic modelling encompasses
Fig. 3 Overview of sentiments in discussions surrounding mobile payments

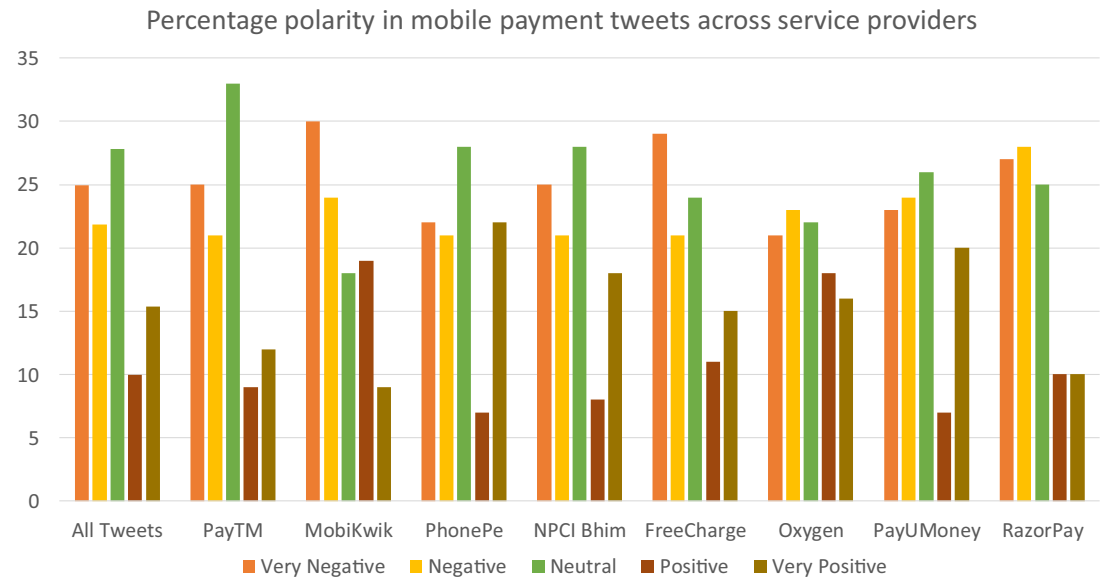


Fig. 4 Network diagram based on topic association after Tweet summarization

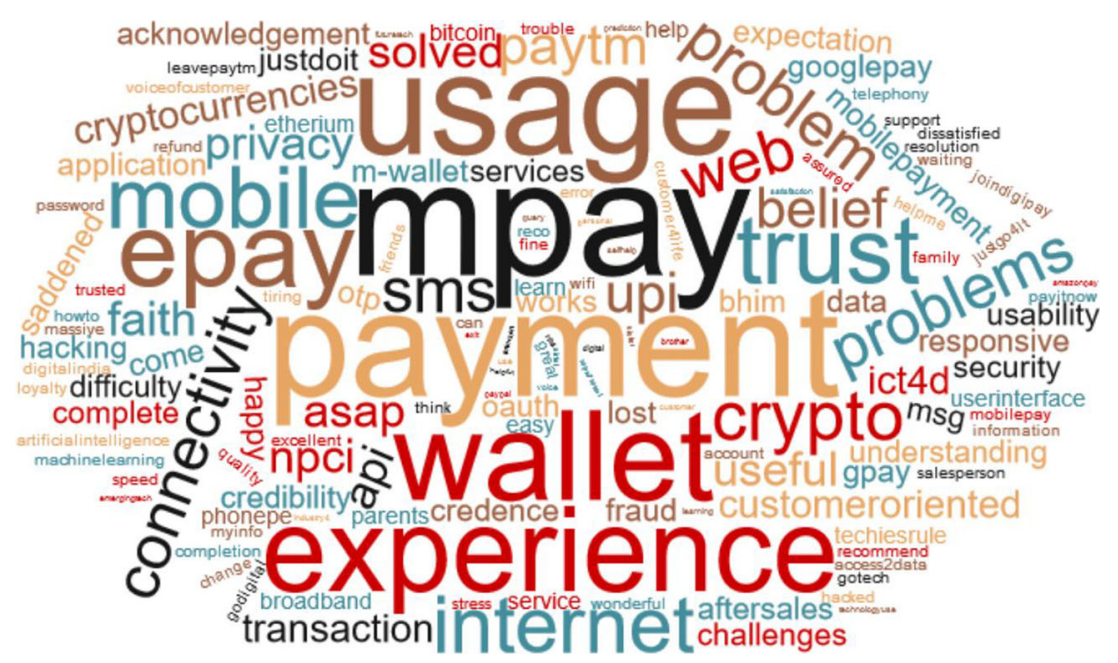

different algorithms which provide an approach in social media analytics whereby large volumes of tweets can be analysed to identify dominant themes within such discussion based on similarity of cooccurrences of the words (Rathore et al. 2017). In this study, Latent Dirichlet Allocation or LDA algorithm (Blei et al. 2003) has been used for topic modelling as it provides a mechanism to control the number of words and topics whereby an analysis towards an empirical model can be developed (Grover et al. 2019a, b, c). Based on the topics which emerged, we went back to literature to identify factors which appear relevant from the topic models. There were 100 topics of fifteen words each that were computed at this stage for further analysis.

After the topic models were used to identify potential factors, we went back to the methodology of content analysis in consumer research (Kassarjian 1977). In the content analysis methodology, coders would look at a context of text and map scores to relevant themes obtained from
Table 3 Results of multiple regression analysis

\begin{tabular}{|c|c|c|c|c|c|}
\hline \multirow[t]{2}{*}{ Model } & \multicolumn{2}{|c|}{ Unstandardized Coefficient } & \multirow{2}{*}{$\begin{array}{l}\text { Standardized Coefficient } \\
\text { Beta }\end{array}$} & \multirow[t]{2}{*}{$\mathrm{t}$} & \multirow[t]{2}{*}{ Sig. } \\
\hline & B & Std. Error & & & \\
\hline 1 (Constant) & 2.981 & 0.611 & & 4.881 & 0.00 \\
\hline Cost & -0.125 & 0.057 & -0.309 & -2.202 & $0.035^{*}$ \\
\hline Usefulness & 0.208 & 0.068 & 0.513 & 3.042 & $0.005 *$ \\
\hline Trust & -0.171 & 0.065 & -0.395 & -2.647 & $0.013 *$ \\
\hline Risk & -0.087 & 0.127 & -2.15 & -0.681 & 0.501 \\
\hline Security & -0.070 & 0.058 & -0.155 & -1.201 & 0.239 \\
\hline Social -Influence & -0.239 & 0.085 & -0.445 & -2.809 & $0.009 *$ \\
\hline Ease of use & -0.007 & 0.058 & 0.017 & 0.121 & 0.904 \\
\hline Performance & -0.022 & 0.061 & -0.050 & -0.358 & 0.723 \\
\hline Credibility & 0.125 & 0.056 & 0.309 & 2.231 & $0.033 *$ \\
\hline Reliability & -0.068 & 0.062 & -0.162 & -1.100 & 0.280 \\
\hline Information Privacy & 0.135 & 0.059 & -0.330 & -2.279 & $0.030 *$ \\
\hline Responsiveness & 0.235 & 0.089 & 0.389 & 2.642 & $0.013 *$ \\
\hline Customer -Attitude & -0.030 & 0.056 & -0.074 & -0.542 & 0.591 \\
\hline Confidentiality & -0.004 & 0.063 & -0.009 & -0.060 & 0.953 \\
\hline Assurance & -0.037 & 0.117 & -0.091 & -0.317 & 0.753 \\
\hline
\end{tabular}

Independent Variables: Predictors: (Constant), Assurance, Confidentiality, Usefulness, Trust, Security, Customer Attitude, Credibility, Reliability, Ease of use, Cost, Information Privacy, Performance, Responsiveness, Socialinfluence, Information-Risk

Dependent Variables: Usage satisfaction, captured through sentiment mining (polarity) of topics

Note: *represent $[\mathrm{p}($ significance value $)<=0.05]$ 
Table 4 Model summary for multiple regression analysis

\begin{tabular}{lllllllll}
\hline $\mathrm{R}$ & $\mathrm{R}^{2}$ & Adj.R & \multicolumn{2}{l}{$\begin{array}{l}\text { Std.Errors } \\
\text { Estimate }\end{array}$} & & \multicolumn{2}{l}{ Change Statistics } \\
\cline { 3 - 8 } & & & & $\mathrm{R}^{2}$ change & F change & Df1 & Df2 & Sig. F change \\
\hline 0.753 & 0.567 & 0.357 & 0.164 & 0.567 & 2.702 & 15 & 31 & 0.009 \\
\hline
\end{tabular}

literature or from data. Content analysis approaches has been recently adopted in consumer centric marketing and information systems literature for mapping topics with themes for theory development (Grover et al. 2018; Grover et al. 2019a, b, c), however such a methodology has never been used for inferential statistics. A word can be a unit of measurement which can be mapped to a theme, which in our case was the identified construct. Category reliability and inter-judge reliability was ensured by creating a three member research team whereby one was having a background of telecommunications research, another coder was having a background in linguistics and the third (author) had a background of information systems research (Kassarjian 1977). The members evaluated all the topic models and assigned scores on a Likert scale to the fifteen factors. Each of the 100 topics could be assigned a score on 15 factors which were identified from the literature (revisit Table 2). The coders agreed on 1438 scores whereby the difference of the mapping among the group of coders did not exceed beyond 1 point on a 5 point Likert scale. The coders did not meet initial inter-judge reliability on 62 decisions. In these 62 decisions, the team went back to revisit the tweets based on a corpus wide word based search whereby after looking at the tweets, the scores were decided consensually after a discussion.
After the topic modelling output was created, it was necessary to evaluate how the topics are interconnected with each other. A network diagram typically can enable a visualization between such topics which co-occur together based on text summarization. Network science is typically used in social media analytics to find out connects among key entities like users and the entities are connected with each other through edges which are typically the strength of the ties (Rathore et al. 2016). The reviews of social media analytics in general and network analytics in particular indicate by doing this activity, it is possible to find out different attributes about the entities which are connected to each other like cluster information, community size, their community strength and many more (Börner et al. 2007; Barabási 2013). The network analysis among the topics enabled us to revalidate the connect of our choice of factors which are used in inferential analysis. In this analysis, individual words within topics, after removing stopwords and completed, were treated as nodes while entity resolution stage, and their cooccurrences is treated as edges. After this stage we proceeded to evaluate the sentiment of these topics using polarity analysis.

Sentiment mining was done to identify the polarity of the topics based on natural language processing using a semantic approach (Rathore et al. 2017). Sentiment analysis can be done on twitter using a variety of approaches to understand
Table 5 Overview of results with Usage Satisfaction as the dependent variable

\begin{tabular}{lllll}
\hline Independent variable & Hypothesis & Beta value & p-value & Result \\
\hline Cost & H1 & -0.309 & 0.035 is less than 0.05 & Accepted \\
Usefulness & H2 & 0.513 & 0.005 is less than 0.05 & Accepted \\
Trust & H3 & -0.395 & 0.013 is less than 0.05 & Accepted \\
Information-Risk & H4 & -2.15 & 0.501 is greater than 0.05 & Rejected \\
Security & H5 & -0.155 & 0.239 is greater than 0.05 & Rejected \\
Social-influence & H6 & -0.445 & 0.009 is less than 0.05 & Accepted \\
Ease of use & H7 & 0.017 & 0.904 is greater than 0.05 & Rejected \\
Performance & H8 & -0.050 & 0.723 is greater than 0.05 & Rejected \\
Credibility & H9 & 0.309 & 0.033 is less than 0.05 & Accepted \\
Reliability & H10 & -0.162 & 0.280 is greater than 0.05 & Rejected \\
Information Privacy & H1 & -0.330 & 0.030 is less than 0.05 & Accepted \\
Responsiveness & H12 & 0.389 & 0.013 is less than 0.05 & Accepted \\
Customer-Attitude & H13 & -0.074 & 0.591 is greater than 0.05 & Rejected \\
Confidentiality & H14 & -0.009 & 0.953 is greater than 0.05 & Rejected \\
Assurance & H15 & -0.091 & 0.753 is greater than 0.05 & Rejected \\
\hline
\end{tabular}


the user generated content (Chang and Chen 2019). In this study, the Stanford CoreNLP toolkit was used for this scoring of sentiments in terms of polarity (Manning et al. 2014). Twitter based studies attempting to infer theoretical meaning from user generated content has often used this package (Grover et al. 2018; Grover et al. 2019a, b, c). This model is adopted since this approach allows tokenization, have a very large semantic library and has reasonable high accuracy for analysis of English library (Manning et al. 2014). For each topic, a 5 point sentiment score was computed using this methodology and then mapped with the outputs of the content analysis of the topic models. This was the matrix which was taken forward for the inferential analysis in the subsequent stage.

The multivariate analysis undertaken was conducted with multiple regression analysis to bring out the relationships among the factors along with inferential impacts on the dependent variable, namely usage satisfaction, to validate the hypothesis proposed in the theoretical development stage. Since the content analysis methodology had met high interjudge reliability and validity, the inferential analysis safely assumes that there are very low multi-collinearity effects, if any, with the data and thus multiple regression analysis is sufficient for inferential analysis (Gefen et al. 2000). The low scores of correlation analysis among the independent constructs validated this assumption. The flowchart of the sequence of activities undertaken for this analysis is illustrated for simplification in Fig. 2.

\section{Results and Findings}

In this research, collected data were analysed to identify customer perception of mobile payments services using a mix of methods of social media analytics which emerge from computer science and inferential statistical analysis which has its roots in terms of applications in social science research.

\subsection{Insights from Social Media Analytics}

First we illustrate the results of the sentiment analysis (polarity analysis) of the tweets mentioning the service provider, individually and collectively. In general, it is seen, more tweets in such mentions are having a negative polarity, as has been illustrated in Fig. 3.

From Fig. 3, it is evident from the polarity analysis of tweets that majority of the users mention a service provider only when they are somewhat dissatisfied with the service. A

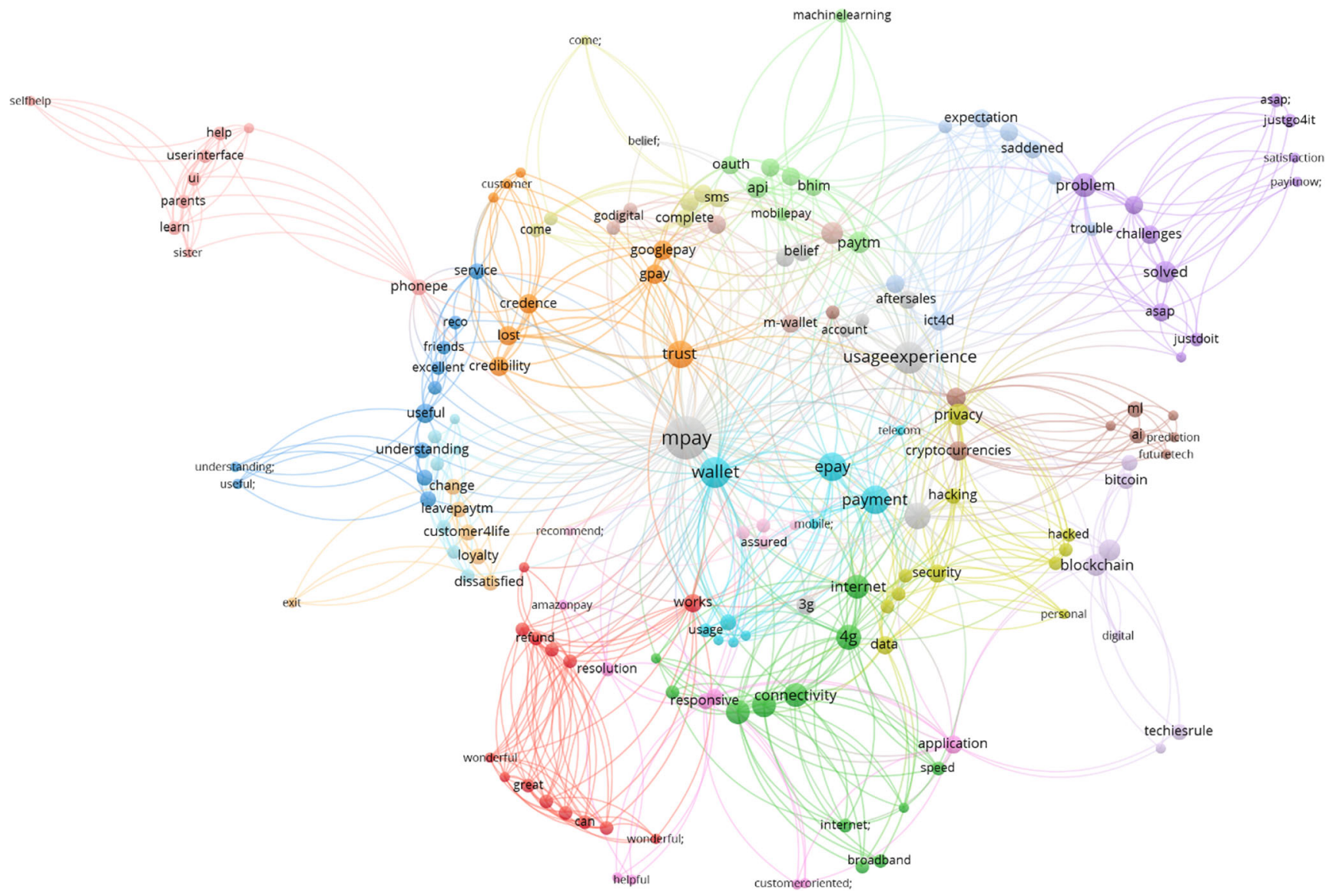

Fig. 5 Word cloud of cleaned topics derived with LDA after tweet summarization 
manual investigation of the tweets which are neutral indicated that these are mostly those which have no emotional words associated and mostly reflected news or informational content from blogs. Alternatively, users have to be delighted in some way that was unexpected for them to mention a payment service provider in tweets.

Subsequently, we attempted to visualize the 100 topics which were identified from the tweets by using a word cloud based method. The stop words which were identified were deleted in the topics which were computed. Further the incomplete words in the topic models or words which had spelling mistakes were corrected before this analysis. In this approach, words which appear more frequently among the topics has a larger font size as compared to the words which have lesser frequency among the topics.

From the wordcloud created from the topics derived through the LDA algorithm, it is evident that a lot of focus is on words like mpay, payment, usage experience, epay, wallet, internet, problems, connectivity, trust and many others. However from the word cloud it is not possible to understand how these words or themes are connected with each other, which can be understood with a network diagram.

Subsequently, we attempted to develop the network diagram based on association among the words derived out of topic modelling. This network diagram could help us cluster the associated words together into closely occurring themes. The network diagram should validate the nature of constructs that was identified from existing literature from different theoretical models, based on the words co-occurring together in a cluster. The network diagram is illustrated in Fig. 4, where classes are indicated with a colour, and each class indicates a concept that is captured by words co-occurring together in a topic derived from tweet summarization using LDA.

The network analysis highlighted there were 17 themes, based on association among the words. Such association can be defined by using constructs, if one attempts to look back into existing literature to find out possible names for the clusters. It is however possible that more than one cluster based on the association among words, may be used to represent a construct representing a concept which could be useful for explaining a theoretical model.

Finally, after completing the analysis of the topic association which emerged after tweet summarization and mapping the topics to the constructs from existing literature, we attempted to validate the model using multivariate statistics like multiple regression analysis.

\subsection{Insights from Multiple Regression Analysis}

Multiple regression analysis was done to identify which factors have a positive influence on mobile payments services. For this, we defined the fifteen hypotheses, and to test each of the hypotheses independently by considered Pearson's chi- square column to identify p-value, only those hypotheses were accepted whose p-value is less than or equal to 0.05 . Therefore, the hypothesis surrounding constructs such as cost, usefulness, trust, social-influence, credibility, tangibility, responsiveness was significantly associated with user's perception towards mobile payments service because the significance value of this hypothesis was less than 0.05 . Therefore, hypothesis such as H1, H2, H3, H6, H9, H11, and H12 was accepted. However hypothesis such as information-risk (H4), security (H5), ease of use (H7), performance (H8), reliability (H10), Customer-attitude (H13), confidentiality (H14), assurance (H15) were not accepted because the p-value of this relationship were greater than 0.05 . The result of the regression analysis is illustrated in Table 3.

The model summary is illustrated in Table 4, was developed to identify the value of $\mathrm{R}^{2}$ which explains the explainability of the model. In this model, the value of $\mathrm{R}^{2}$ is 0.567 for the constructs usage satisfaction for mobile payments services in India which interprets that assurance, confidentiality, usefulness, trust, security, customer attitude, credibility, reliability, ease of use, cost, information privacy, performance, responsiveness, social- influence, and informationrisk variables can explain the variance towards predicting usage satisfaction to the extent of $56.7 \%$. The significance value of this model was 0.009 , therefore, this model is accepted.

In Table 5, an overview of the hypothesis which were validated and the results of the validation is illustrated. Out of the 15 constructs which were identified from the topic models, 7 relationships were accepted. The relatively lower number of relationships being accepted could be due to the noise which typically is present in social media discussions. While topic modelling captures the variety of discussions, it also captures factors which demonstrate low occurrences among the tweets in general and topic models in particular.

\section{Discussion}

In this study, we attempted to identify factors that affect usage experience from service encounters in mobile payments. The study attempted to extend and connect different theories of technology adoption with service science and service quality literature to predict the usage satisfaction of mobile payment based on user generated content surrounding a specific service encounter. The validation was done using user generated content which was mined on the service provider in Twitter. In this study, 400,242 tweets were mined using methods of social media analytics like topic modelling, sentiment mining and network analysis. Then using content analysis method, the descriptive outputs were mapped objectively to key constructs identified from literature. This allowed us to propose the new theoretical model, namely DSUSM. Subsequently, multivariate analysis was undertaken to validate the proposed 
DSUSM model. Our first thematic contribution in the domain of digital services in general and mobile payments in particular addresses a gap in existing customer experience literature where for digital services, accessing customer experience at the point of service consumption or service encounter becomes difficult to measure (Becker and Jaakkola 2020). This is where the dependent variable of our study, namely, usage satisfaction, addresses and highlights a novel way to operationalize this measure. In such a background, we attempt to discuss the individual findings of our study. The second thematic contribution is showcasing an approach within big data analytics driven research, whereby theory building in information systems can be attempted through a combination of computational and social research methodologies. Such directions are often highlighted in existing editorials that studies in big data need to move away from the data towards theory building (Berente et al. 2019; Grover et al. 2020).

Within the domain contribution, our first finding (Fig. 3) indicates that a much larger corpus among the tweets which were obtained in this approach were having negative polarity, as compared to positive polarity. This finding could be triggered due to multiple reasons as per existing literature (Jansen et al. 2009). Often users do not share their experiences unless they are extremely delighted about a product or service which may have aspirational features. Mobile payments would be used predominantly as a service to access a different product or service which may trigger aspirational emotions or delight. Since mobile payments do not have too many aspirational features for most people, the service encounters of positive experiences did not trigger tweets on the positive encounters of the service. However, many users when they are dissatisfied often complain to the brand in the hope for a timely resolution for the complaint (Sparks et al. 2016). This leads to having higher number of tweets with slightly negative and negative polarity. Further many tweets, which often do not have highly polarizing words, may be reflected as a neutral tweet, which is basically the methodological limitation of many algorithms for sentiment analysis (Rathore et al. 2017).
In the second finding (Fig. 5), we had identified the major themes from the topic modelling using LDA, which was undertaken for summarizing the core focus of the tweets. The wordcloud demonstrates the key topics which were discussed in such tweets. Words which are available in the word cloud can easily be mapped to existing constructs in service science and adoption literature. However there was a need to group words so that thematically they can be grouped together based on usage among many customers. The network science outcome (Fig. 4) highlights which of the words co-occurred together in the topic models and it helped us to identify possible factors from existing literature. Fifteen clusters were derived from this analysis, as indicated in the colour coding. Then looking at the words in the cluster and reflecting upon existing literature, fifteen factors could be identified for developing the DSUSM for further validation.

The initial proposed model integrated technology adoption literature, extended technology adoption literature and service science literature. Fifteen constructs were identified from the analysis of unstructured data for proposing the DSUSM model. However our inferential analysis as illustrated in Table 5 indicates that in the context of mobile payments usage in India, seven factors like cost, usefulness, trust, social-influence, credibility, information privacy and responsiveness have higher impacts. Subsequently, it was also identified that the remaining eight factors like information risk, security, ease of use, performance, reliability, customer-attitude, confidentiality and assurance have lower impacts. It is important to note that the sample who use social media are technically more savvy than new technology users. So while adoption and service quality literature highlights the importance of factors like ease of use, performance and reliability, they are not considered by the users as being important while estimating usage satisfaction. We have defined this and elaborated usage satisfaction a bit more in this context. In this context, it is important to note that despite all evidences of ease of use being extremely critical to adoption of new technology (Rana et al. 2013), it does not have any significant impact on the usage
Fig. 6 Final DSUSM for assessing usage satisfaction in mobile payments

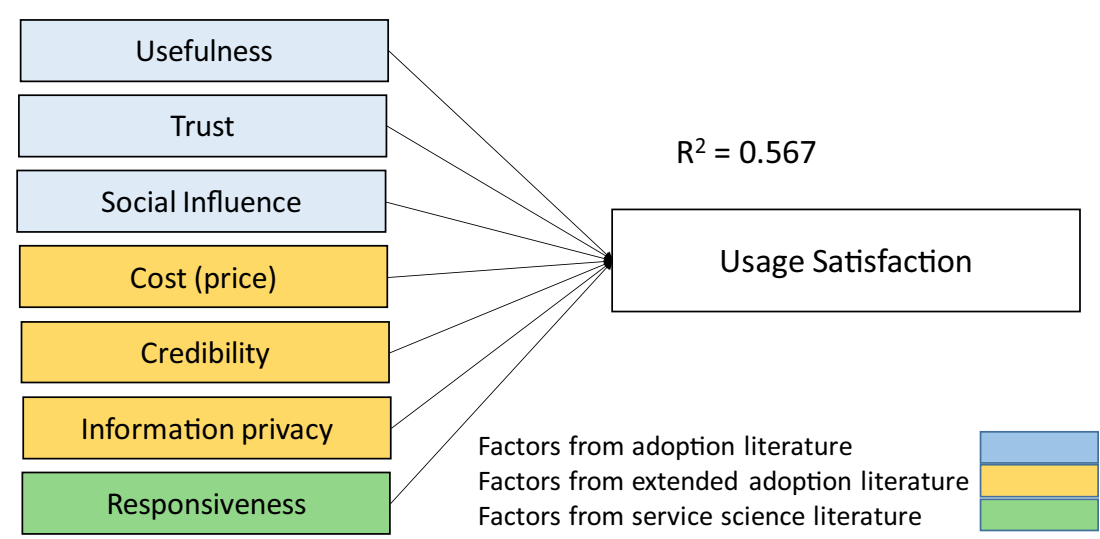


satisfaction of technologies that users frequently use. This difference in importance could be because the user groups are already very technology friendly and do not face challenges while using this technology. So factors which often have very high impact in the adoption of new technology has less relevance in the usage satisfaction of digital services once they are used frequently. The technology is also somewhat mature, and so reliability issues of the application crashing may be very less. Further, the theories we have adopted is from IS adoption and service quality literature. However it is important to note that our dependent variable, usage satisfaction, which we have attempted to measure using topic modelling and sentiment mining, is very different from both adoption literature and service quality literature. Hence while a different exploration of research on usage as a dependent variable, may continue to have these factors being relevant, the usage experience is not being explained statistically through these parameters. These factors definitely have some importance, as has been brought out in our topic modelling, but statistically lower importance in explaining the variation of the dependent variable "usage satisfaction". Recent literature has indicated that value of such mobile payment platforms are driven by self congruence and novelty but also faces threat from unintended consequences of usage of new technology (Karjaluoto et al. 2019; Gong et al. 2020). Our findings are complementing these findings that for users who are technology friendly, such challenges and theories of resistance are minimal in impacting usage satisfaction.

\subsection{Implications for Theory}

The theoretical implications of our study are in two folds. First we make theoretical contribution in proposing a new model for measuring digital service usage satisfaction. Further we also make a methodological contribution in which we present an approach to develop inferential theoretical models using social media data.

Mobile payments services are one of the convenient and effective methods for winning greater market share in this real environment (Bohle et al. 2000). An initial look at the overview of large volumes of user generated content and then connecting it with adoption and service science literature indicates factors like cost advantage, usefulness, trust, information risk, security, social influence, ease of use, performance, credibility and information privacy could be relevant (Slade et al. 2013, 2015; Kapoor et al. 2014; Pachpande and Kamble 2018; Gong et al. 2020). In this study we extend the understanding surrounding the use of mobile payment services and its impacts on the consumer in an emerging economy like India. Existing literature on mobile payment usage in India indicates that facilitators like price benefit, network externalities, trust, and habit and barriers like lack of facilitating conditions, risk and operational constraints impact the use of mobile payments ( $\mathrm{Pal}$ et al. 2020). Further technology readiness and privacy concerns impact adoption of mobile payments in India. However, none of these studies attempted to explore the antecedents which impacts usage satisfaction among the users. In fact, it is interesting to know that, which customer experience during service encounter has been a widely explored topic, antecedents of usage satisfaction or customer experience in the digital context is yet to be explored in existing literature (Becker and Jaakkola 2020). Usage satisfaction has been identified in existing literature as being key towards impacting adoption and use of technology enabled services. Our study highlight that among the digital literate population, factors like cost, usefulness, trust, social-influence, credibility, information privacy and responsiveness drive mobile payment service experiences and affect the usage satisfaction. These antecedents extend understanding surrounding established factors like responsiveness, price benefits and information security and privacy for engagement and customer satisfaction which are already identified in existing literature based on user generated content in social media (Agnihotri et al. 2016; Grover and Kar 2020). The impact of these constructs have never been explored in the context of satisfaction from any technology or technology enabled service usage. The proposed DSUSM model is one of a kind, whereby we develop a relationship among these theoretical frameworks and connect technology adoption models, extended technology adoption models and service science literature for estimating usage satisfaction. Since the individual constructs are well established, future research can also attempt to revalidate this model or its extension, in different cultural context, technological context or service context. Figure 6 illustrates the final model that was derived after validating the model with multiple regression analysis.

In this study, we have taken the mixed research methodology approach by combining social media analytics with multivariate analysis to identify the salient factors for successful and effective implementation of mobile payments services in India. Qualitative analysis is used to analyse the text data by performing content analysis, content analysis is used to perform sentiments analysis and topic modelling in the data that is collected from social media sites such as Twitter (Bhattacherjee 2012). The approach of using content analysis method for converting topic models to factors which can be validated for an inferential theoretical model, has not been attempted in existing literature. Since we used social media sites such as Twitter for data collection instead of data collected from survey forms, therefore its approach presents a novelty in itself when applied to connect methodologies for theory building which are otherwise disconnected in existing literature (Wang et al. 2018; Buntain et al. 2016; Grover et al. 2018). These methods have never been connected for 
validating inferential models based on user generated content, and this approach is another major contribution in this study.

The need for integrating inferential model or statistical analysis with the output of social media analytics is highlighted in this study itself. The descriptive findings which typically are obtained from social media analytics through network science or text mining, while is very information rich, it also has a lot of noise. As indicated from the outcome of the topic models and community analysis among topic modelling words, fifteen constructs were identifiable very distinctly. However, the statistical analysis whereby we attempted to regress these constructs with the dependent variable (namely, usage satisfaction) indicated that seven factors are actually statistically significant. This indicates, while inferences directly from the visualization outputs may always not be very statistically significant, although the information may be relevant. Thus, for better reliability of the theoretical model and propositions, it is necessary to convert all such visualization output of "Big Data" to a form where they can be statistically validated, to the extent possible. Methodologically, this requires a methodological move away from the approach, many of the studies which use "Big Data" adopt for theorizing in social, political or industrial domains of management literature. Such an approach which extends descriptive findings of social media analytics with statistical analysis is likely to enhance the internal and external validity of the research methodology and hence the generalizability of the findings.

\subsection{Implications for Practice}

Our study highlights that factors like cost, usefulness, trust, social-influence, credibility, information privacy and responsiveness drive mobile payment service experiences and affect the usage satisfaction. So in line with these findings, service providers in India should attempt to minimize the cost of transactions. This could be positively impacted by reducing any fee per transaction during such mobile payments between parties. Higher cashbacks may also positively impact the factor like cost which has a positive impact on the usage satisfaction. Further, the usefulness of these apps can be enhanced, if they serve not only as a payment platform, but their usefulness can be enhanced towards availing other related services. For example, if the platform can enable payments not only which are peer to peer, but also for bills and utilities like electricity, phone bills, credit card bills, gas bills, fee payment, road taxes, ticketing needs and other payments, it will enhance the usefulness of the mobile application extensively. A market research can be undertaken for identifying such related services. In this context, social media discussions may also be mined for establishing complementary needs based on users of other similar services (Hall-Phillips et al. 2016).

Trust and credibility can be built by service providers through efforts made in branding, possibly through influencers with credence. To build trust, sharing evidences of audits from third parties who are trusted may be helpful. Customers may have greater trust on the mobile payment service provider if frequently evidences of positive experiences and growth of "satisfied customer base" can be shared with customers. For example, after every transaction if customers are asked about the feedback or rating, and periodically, the service providers could share with the customer, how many of the service encounters were absolutely delightful. Further, attempts may be made to frequently communicate when users share their data in transactions, that their information is not only secure, but it will not be shared without their explicit permission within or outside the firm, for any unintended usage. Such communication on how the firm is respecting and withholding the privacy of the user can help a lot in driving usage satisfaction. Also attempts may be made not to access information or seek access rights for which the mobile application may not have explicit connect. For example, a mobile application may not seek access rights to the camera, unless there is a face recognition component in the software for verifying the credentials of the user who is initiating the transaction. Similarly, a mobile application may not need access to location data unless specific use cases require permissions for using location data for providing specific utility to the user of the service. Feedback surrounding the efficacy of such implementations can also be sought in social media (Grover and Kar 2020).

Last but not the least, if problems are faced by users and they complain, an instant acknowledgement that their complaint is registered and frequently updating them on the status of their complaint, can help to address concerns surrounding responsiveness of the service provider. Further to impact responsiveness, the firms could enhance the speed at which complaints raised across channels surrounding failures of transactions are addressed through artificial intelligence driven technologies like chatbots whereby the platform helps first by getting the complaint recorded, second by communicating the time to be taken for the issue to be resolved and third ensuring the resolution as per promised timelines by defining a problem escalation workflow based on criticality. Such chatbots may hugely impact the customer relationship management and impact positively the responsiveness perceived by the customer when any challenge is faced from the use of a digital payment platform. Responsiveness in social media enhances overall customer satisfaction (Agnihotri et al. 2016).

\subsection{Limitations and Future Research Directions}

This study has certain limitations, First, in this study, 400,242 tweets were collected in which we apply social media analytics and multi-variate analytics techniques. This sample is technology friendly and uses the internet extensively and thus less representative of users who may be using such digital 
payment platforms less frequently. So findings are likely to be based on user groups who are technology friendly and have high usage. Second, this study was focused only on popular mobile payments services used in India. Most of the findings and tweets were related to PayTM and BHIM. While sampling was attempted across studies, the usage behaviour across these platforms were heavily skewed. Third, this study has not attempted to compare which mobile payments services were better in terms of usage satisfaction. Future research could also focus on factors which affect the prioritization of service providers by users. Fourth in this study we were taken only fifteen factors to identify the influence rate of the mobile payments services. The current study can be extended if the data collection methodology were to be enhanced by addressing some biases of users in terms of expressing their service encounters. This maybe done if a longer duration of data collection could have been undertaken and a longitudinal study been done with the data.

Methodologically, the approach which has been highlighted can be used in future studies for exploring validation of theoretical models based on user generated content. This would in particular be relevant if data driven inductive research is undertaken for contributing to the domain of information systems. Such mixed method approaches which analyse data using multiple methodologies to provide complementary insights on why specific trends are revealed based on data have been promoted in editorials in information systems (Berente et al. 2019; Grover et al. 2020). Such studies which adopt similar approaches may attempt to explore antecedents of use, adoption, impact or other behavioural Further, only the social media content that was in English was capture for the current analysis. So future research could also look towards exploring more socio-cultural elements of service encounters and usage experiences in future studies. Future research can also try to improve upon this approach methodologically by developing approaches whereby better measures for internal and external validity can be demonstrated.

\section{Conclusion}

This research tries to explore the drivers of usage experience based on social media data of mobile payments service users on Twitter. An inferential research model is proposed, namely, DSUSM, and attempt to validate the model statistically using Twitter data. The model development stage based on topics identified from text summarization of tweets highlights the relevance of factors like assurance, confidentiality, usefulness, trust, security, customer attitude, credibility, reliability, ease of use, cost, information privacy, performance, responsiveness, social- influence, and information risk. Afterwards based on inferential analysis using regression; factors like cost, usefulness, trust, credibility, social-influence, information-privacy and responsiveness have been identified to have a significant influence on the adoption of mobile payments services. If these factors are addressed perfectly by the mobile payments service providers, then the adoption rate of mobile payments services is expected to increase automatically. This is the first study which identified factors relevant for increasing the usage satisfaction towards mobile payments services based on user generated content.

\section{References}

Agnihotri, R., Dingus, R., Hu, M. Y., \& Krush, M. T. (2016). Social media: Influencing customer satisfaction in B2B sales. Industrial Marketing Management, 53, 172-180.

Ajzen, I. (1991). The theory of planned behaviour. Organizational Behavior and Human Decision Processes, 50(2), 179-211.

Ajzen, I., \& Fishbein, M. (1977). Attitude-behavior relations: A theoretical analysis and review of empirical research. Psychological Bulletin, 84 No(5), 888-918.

Albashrawi, M., \& Motiwalla, L. (2019). Privacy and personalization in continued usage intention of mobile banking: An integrative perspective. Information Systems Frontiers, 21 No(5), 1031-1043.

Amin, H. (2008). Factors affecting the intentions of customers in Malaysia to use mobile phone credit cards. Management Research News, 31 No(7), 493-503.

Arif, A. S. M., \& Du, J. T. (2019). Understanding collaborative tourism information searching to support online travel planning. Online Information Review, 43 No(3), 369-386.

Arvidsson, N. (2014). Consumer attitudes on mobile payment servicesresults from a proof of concept test. International Journal of Bank Marketing, $32 \mathrm{No}(2), 150-170$.

Aswani, R., Kar, A. K., Ilavarasan, P. V., \& Dwivedi, Y. K. (2018). Search engine marketing is not all gold: Insights from Twitter and SEOClerks. International Journal of Information Management, 38 No(1), 107-116.

Barabási, A. L. (2013). Network science. Philosophical Transactions of the Royal Society A: Mathematical, Physical and Engineering Sciences, 371, 20120375.

Becker, L., \& Jaakkola, E. (2020). Customer experience: fundamental premises and implications for research. Journal of the Academy of Marketing Science, 48, 1-19. https://doi.org/10.1007/s11747-01900718-x.

Berente, N., Seidel, S., \& Safadi, H. (2019). Research commentarydata-driven computationally intensive theory development. Information Systems Research, 30(1), 50-64.

Berthon, P. R., Pitt, L. F., Plangger, K., \& Shapiro, D. (2012). Marketing meets Web 2.0, social media, and creative consumers: Implications for international marketing strategy. Business Horizons, $55 \mathrm{No}(3)$, 261-271.

Bhattacherjee, A. (2012), Social Science Research: Principles, Methods, and Practices. 2nd ed. Open Access Textbooks..

Blei, D. M., Ng, A. Y., \& Jordan, M. I. (2003). "Latent Dirichlet Allocation”. Journal of Machine Learning Research, 3(Jan), 9931022.

Bohle, K., Krueger, M., Herrmann, C., Carat, G., \& Maghiros, I. (2000), "Electronic payment systems-Strategic and technical issues", available at: http://ftp.jrc.es/EURdoc/eur19933en.pdf (accessed June 10, 2019). 
Börner, K., Sanyal, S., \& Vespignani, A. (2007). Network science. Annual review of information science and technology, 41 No(1), 537-607.

Brown, S. A., \& Venkatesh, V. (2005). Model of adoption of technology in households: A baseline model test and extension incorporating household life cycle. MIS Quarterly, 29 No(3), 399-426.

Buntain, C., McGrath, E., Golbeck, J., \& LaFree, G. (2016). Comparing social media and traditional surveys around the Boston Marathon bombing. In \# Micro posts (pp. 34-41).

Chang, H. H., \& Wang, H. W. (2011). The moderating effect of customer perceived value on online shopping behaviour. Online Information Review, 35 No(3), 333-359.

Chang, W. L., \& Chen, Y. P. (2019). Way too sentimental? a credible model for online reviews. Information Systems Frontiers, 21 No(2), 453-468.

Chatterjee, S., \& Kar, A. K. (2020). Why do small and medium enterprises use social media marketing and what is the impact: Empirical insights from India. International Journal of Information Management, 53, 102103.

Chaudrie, J., \& Dwivedi, Y. K. (2005). A survey of citizens' awareness and adoption of e-government initiatives, the 'government gateway': A United Kingdom perspective. Iseing. Org, 5 No, 1-13.

Chhonker, M. S., Verma, D., \& Kar, A. K. (2017). Review of technology adoption frameworks in mobile commerce. Procedia Computer Science, 122, 888-895.

Chhonker, M. S., Verma, D., Kar, A. K., \& Grover, P. (2018). mcommerce technology adoption: Thematic and citation analysis of scholarly research during (2008-2017). The Bottom Line, 31 No(3/4), 208-233.

Dahlberg, T., Mallat, N., Ondrus, J., \& Zmijewska, A. (2008). Past, present and future of mobile payments research: A literature review. Electronic commerce research and applications, 7 No(2), 165-181.

Davis, F. D. (1989). Perceived usefulness, perceived ease of use, and user acceptance of information technology. MIS Quarterly, 13 No(13), 319-340.

Dwivedi, Y. K., Khan, N., \& Papazafeiropoulou, A. (2007). Consumer adoption and usage of broadband in Bangladesh. Electronic Government-An International Journal, 4 No(3), 299-313.

Dwivedi, Y. K., Rana, N. P., Jeyaraj, A., Clement, M., \& Williams, M. D. (2019). Re-examining the unified theory of acceptance and use of technology (UTAUT): Towards a revised theoretical model. Information Systems Frontiers, 21(No3), 719-734.

Flavian, C., Guinalíu, M., \& Gurrea, R. (2006). The role played by perceived usability, satisfaction and consumer trust on website loyalty. Information \& Management, $43 \mathrm{No}(1), 1-14$.

Gefen, D., Straub, D., \& Boudreau, M. C. (2000). Structural equation modeling and regression: Guidelines for research practice. Communications of the Association for Information Systems, 4 $\mathrm{No}(7), 1-64$.

Gholami, R., Ogun, A., Koh, E., \& Lim, J. (2010). " Factors affecting epayment adoption in Nigeria". Journal of Electronic Commerce in Organizations, $8 \mathrm{No}(4), 51-67$.

Gong, X., Zhang, K. Z., Chen, C., Cheung, C. M., \& Lee, M. K. (2020). Transition from web to mobile payment services: The triple effects of status quo inertia. International Journal of Information Management, 50, 310-324.

Grover, P., \& Kar, A. K. (2020). User engagement for mobile payment service providers-introducing the social media engagement model. Journal of Retailing and Consumer Services, 53, 101718.

Grover, P., Kar, A. K., \& Davies, G. (2018). Technology-enabled Health"-Insights from Twitter analytics with a socio-technical perspective. International Journal of Information Management, 43, 85-97.

Grover, P., Kar, A. K., \& Ilavarasan, P. V. (2017). Understanding Nature of Social Media Usage by Mobile Wallets Service Providers-An
Exploration through SPIN Framework. Procedia computer science, 122, 292-299.

Grover, P., Kar, A. K., Janssen, M., \& Ilavarasam, P. V. (2019a). Perceived usefulness, ease of use and user acceptance of blockchain technology for digital transactions-insights from user-generated content on Twitter". Enterprise Information Systems, 13 No, 771800. 6 .

Grover, P., Kar, A. K., Dwivedi, Y. K., \& Janssen, M. (2019b). Polarization and acculturation in US Election 2016 outcomes-Can twitter analytics predict changes in voting preferences. Technological Forecasting and Social Change, 145, 438-460.

Grover, P., Kar, A. K., \& Ilavarasan, P. V. (2019c). Impact of corporate social responsibility on reputation - Insights from tweets on sustainable development goals by CEOs. International Journal of Information Management, 48, 39-52.

Grover, V., Lindberg, A., Benbasat, I., \& Lyytinen, K. (2020). The Perils and Promises of Big Data Research in Information Systems. Journal of the Association for Information Systems, 21 No(2), 268-291.

Guriting, P., \& Oly Ndubisi, N. (2006). Borneo online banking: evaluating customer perceptions and behavioural intention. Management research news, 29(1/2), 6-15.

Hall-Phillips, A., Park, J., Chung, T. L., Anaza, N. A., \& Rathod, S. R. (2016). I (heart) social ventures: Identification and social media engagement. Journal of Business Research, 69 No(2), 484-491.

Henderson, M., Johnson, N. F., \& Auld, G. (2013). Silences of ethical practice: dilemmas for researchers using social media. Educational research and evaluation, $19 \mathrm{No}(6), 546-560$.

Hong, S. J., \& Tam, K. Y. (2006). Understanding the adoption of multipurpose information appliances: The case of mobile data services. Information systems research, $17 \mathrm{No}(2), 162-179$.

Howard, D., Mangold, W. G., \& Johnston, T. (2014). Managing your social campaign strategy using Facebook, Twitter, Instagram, YouTube \& Pinterest: An interview with Dana Howard, social media marketing manager. Business Horizons, $5 \& \operatorname{lt}(57), 657-665$. i>No.

Ismagilova, E., Slade, E. L., Rana, N. P., \& Dwivedi, Y. K. (2019). The effect of electronic word of mouth communications on intention to buy: A meta-analysis. Information Systems Frontiers, 21, 1-24.

Jansen, B. J., Zhang, M., Sobel, K., \& Chowdury, A. (2009). Twitter power: Tweets as electronic word of mouth. Journal of the American Society for Information Science and Technology, 60(11), 2169-2188.

Joseph, N., Kar, A. K., \& Ilavarasan, P. V. (2017, November). “A model for prioritization and prediction of impact of digital literacy training Programmes and validation", In Conference on e-Business, eServices and e-Society (pp. 227-238). Springer, Cham.

Jun, M., \& Cai, S. (2001). The key determinants of internet banking service quality: a content analysis. International Journal of bank marketing, $19 \& \operatorname{lt}(7), 276-291$. i>No.

Kapoor, K. K., Dwivedi, Y. K., \& Williams, M. D. (2014). Innovation adoption attributes: a review and synthesis of research findings. European Journal of Innovation Management, 17 No(3), 327-348.

Kapoor, K. K., Tamilmani, K., Rana, N. P., Patil, P., Dwivedi, Y. K., \& Nerur, S. (2018). Advances in social media research: past, present and future. Information Systems Frontiers, $20 \mathrm{No}(3), 531-558$.

Karami, A., Lundy, M., Webb, F., \& Dwivedi, Y. K. (2020). Twitter and research: a systematic literature review through text mining. IEEE Access: Practical Innovations, Open Solutions, 8, 67698-67717.

Karjaluoto, H., Shaikh, A. A., Saarijärvi, H., \& Saraniemi, S. (2019). How perceived value drives the use of mobile financial services apps. International Journal of Information Management, 47, 252 261.

Karnouskos, S. (2004). Mobile payment: a journey through existing procedures and standardization initiatives. IEEE Communications Surveys \& Tutorials, 6(4), 44-66. 
Kassarjian, H. H. (1977). Content analysis in consumer research. Journal of Consumer Research, 4(1), 8-18.

Kassim, N., \& Abdullah, N. (2010). The effect of perceived service quality dimensions on customer satisfaction, trust, and loyalty in ecommerce settings: A cross-cultural analysis. Asia Pacific Journal of Marketing and Logistics, 22, 351-371.

Kim, A. J., \& Ko, E. (2012). Do social media marketing activities enhance customer equity? An empirical study of luxury fashion brand. Journal of Business Research, 65(10), 1480-1486.

Koenig-Lewis, N., Marquet, M., Palmer, A., \& Zhao, A. L. (2015). Enjoyment and social influence: predicting mobile payment adoption. The Service Industries Journal, 35(10), 537-554.

Leong, E. K., Ewing, M. T., \& Pitt, L. F. (2003). Australian marketing managers' perceptions of the internet: a quasi-longitudinal perspective. European Journal of Marketing, 37(3/4), 554-571.

Liang, T. P., \& Huang, J. S. (1998). An empirical study on consumer acceptance of products in electronic markets: a transaction cost model. Decision Support Systems, 24(1), 29-43.

Lin, G. T., \& Sun, C. C. (2009). Factors influencing satisfaction and loyalty in online shopping: an integrated model. Online Information Review, 33(3), 458-475.

Lin, H. F. (2013). Determining the relative importance of mobile banking quality factors. Computer Standards \& Interfaces, 35(2), 195-204.

Loiacono, E. T., Watson, R. T., \& Goodhue, D. L. (2007). WebQual: An instrument for consumer evaluation of web sites. International Journal of Electronic Commerce, 11(3), 51-87.

Mallat, N. (2007). Exploring consumer adoption of mobile payments-A qualitative study. The Journal of Strategic Information Systems, 16(4), 413-432.

Mangold, W. G., \& Faulds, D. J. (2009). Social media: The new hybrid element of the promotion mix. Business Horizons, 52(4), 357-365.

Manning, C. D., Surdeanu, M., Bauer, J., Finkel, J. R., Bethard, S., \& McClosky, D. (2014). The Stanford CoreNLP natural language processing toolkit. In Proceedings of 52nd annual meeting of the association for computational linguistics: system demonstrations (pp. 55-60).

Meharia, P. (2012). Assurance on the reliability of the mobile payment system and its effects on its use: an empirical examination. Accounting and Management Information Systems, 11(1), 97-111.

Mir, U. B., Kar, A. K., Dwivedi, Y. K., Gupta, M. P., \& Sharma, R. S. (2019). Realizing digital identity in government: Prioritizing design and implementation objectives for Aadhaar in India. Government Information Quarterly, 37(2), 101442.

Mohan, R., \& Kar, A. K. (2017, November). \#Demonetization and its impact on the Indian economy-insights from social media analytics. In Conference on e-Business, e-Services and e-Society (pp. 363 374). Springer, Cham.

Mukherjee, T., Ilavarasan, P. V., \& Kar, A. K. (2019). Digital literacy training, impact \& moderating role of perceived value among unemployed women in India. In Proceedings of the Tenth International Conference on Information and Communication Technologies and Development (pp. 1-4).

Mustafa, S. Z., Kar, A. K., \& Janssen, M. F. W. H. A. (2020). Understanding the impact of digital service failure on users: Integrating Tan's failure and DeLone and McLean's success model. International Journal of Information Management, 53, 102119.

Neiger, B. L., Thackeray, R., Van Wagenen, S. A., Hanson, C. L., West, J. H., Barnes, M. D., \& Fagen, M. C. (2012). Use of social media in health promotion: purposes, key performance indicators, and evaluation metrics. Health Promotion Practice, 13(2), 159-164.

Oh, O., Eom, C., \& Rao, H. R. (2015). Role of social media in social change: An analysis of collective sense making during the 2011 Egypt revolution. Information Systems Research, 26(1), 210-223.

Oliver, R. L. (1994). Conceptual issues in the structural analysis of consumption emotion, satisfaction, and quality: Evidence in a service setting. Advances in Consumer Research, 21, 16-22.
Omwansa, T.(2009). M-PESA: Progress and Prospects. Innovations, Mobile World Congress, pp. 107-123.

Pachpande, B. R., \& Kamble, A. A. (2018). Study of e-wallet awareness and its usage in Mumbai. Journal of Commerce and Management Thought, 9(1), 33-45.

Pal, A., Herath, T., De', R., \& Rao, H. R. (2020). Contextual facilitators and barriers influencing the continued use of mobile payment services in a developing country: Insights from adopters in India. Information Technology for Development (pp. 1-27).

Paniagua, J., \& Sapena, J. (2014). Business performance and social media: Love or hate? Business Horizons, 57(6), 719-728.

Papa, F., Livi, S., Cornacchia, M., Nicolò, E., \& Sapio, B. (2010). Factors affecting the usage of payment services through digital television in Italy. In Proceedings of the 8th European Conference on Interactive TV and Video (pp. 209-216). New York City: ACM.

Parasuraman, A., Berry, L. L., \& Zeithaml, V. A. (1991). Understanding customer expectations of service. Sloan Management Review, 32(3), $39-48$.

Parasuraman, A., Zeithaml, V. A., \& Berry, L. L. (1988). SERVQUAL: A multiple-item scale for measuring consumer perception of service quality. Journal of Retailing, 64(1), 12-40.

Peha, J. M., \& Khamitov, I. M. (2004). PayCash: a secure efficient Internet payment system. Electronic Commerce Research and Applications, 3(4), 381-388.

Puschmann, T. (2017). Fintech. Business \& Information Systems Engineering, 59(1), 69-76.

Rana, N. P., Dwivedi, Y. K., \& Williams, M. D. (2013). Evaluating alternative theoretical models for examining citizen centric adoption of e-government. Transforming Government: People, Process and Policy, 7(1), 27-49.

Rana, N. P., Dwivedi, Y. K., Lal, B., Williams, M. D., \& Clement, M. (2017). Citizens' adoption of an electronic government system: towards a unified view. Information Systems Frontiers, 19(3), 549568.

Rathore, A. K., \& Ilavarasan, P. V. (2020). Pre-and post-launch emotions in new product development: Insights from twitter analytics of three products. International Journal of Information Management, 50, 111-127.

Rathore, A. K., Kar, A. K., \& Ilavarasan, P. V. (2017). Social media analytics: Literature review and directions for future research. Decision Analysis, 14(4), 229-249.

Rogers, E. M. (1995). Diffusion of Innovations (4th Eds.). New York: ACM The Free Press (Sept. 2001), pp. 15-23.

Salo, J., \& Karjaluoto, H. (2007). A conceptual model of trust in the online environment. Online Information Review, 31(5), 604-621.

Sebastianelli, R., \& Tamimi, N. (2018). E-tailer website attributes and trust: understanding the role of online reviews. Online Information Review, 42(4), 506-519.

Shafinah, K., Sahari, N., Sulaiman, R., Yusoff, M. S. M., \& Ikram, M. M. (2013). Determinants of user behavior intention (BI) on mobile services: A preliminary view. Procedia Technology, 11, 127-133.

Shin, D. H. (2009). Towards an understanding of the consumer acceptance of mobile wallet. Computers in Human Behavior, 25(6), $1343-1354$.

Shon, T. H., \& Swatman, P. M. (1998). Identifying effectiveness criteria for Internet payment systems. Internet Research, 8(3), 202-218.

Slade, E. L., Dwivedi, Y. K., Piercy, N. C., \& Williams, M. D. (2015). 'Modeling consumers' adoption intentions of remote mobile payments in the United Kingdom: extending UTAUT with innovativeness, risk, and trust. Psychology \& Marketing, 32(8), 860-873.

Slade, E. L., Williams, M. D., \& Dwivedi, Y. K. (2014). Devising a research model to examine adoption of mobile payments: An extension of UTAUT2. The Marketing Review, 14(3), 310-335.

Slade, E. L., \& Williams, M. D. and Yogesh Dwivedi. (2013). Extending UTAUT2 To Explore Consumer Adoption of Mobile Payments. UK 
Academy for Information Systems Conference Proceedings 2013. No. 36.

Southard, P. B., \& Siau, K. (2004). A survey of online e-banking retail initiatives. Communications of the ACM, 47(10), 99-102.

Sparks, B. A., So, K. K. F., \& Bradley, G. L. (2016). Responding to negative online reviews: The effects of hotel responses on customer inferences of trust and concern. Tourism Management, 53, 74-85.

Stewart, K. A., \& Segars, A. H. (2002). An empirical examination of the concern for information privacy instrument. Information Systems Research, 13(1), 36-49.

Tamilmani, K., Rana, N. P., \& Dwivedi, Y. K. (2020). Consumer acceptance and use of information technology: A meta-analytic evaluation of UTAUT2. Information Systems Frontiers, 20, 1-19.

Tan, W. K., \& Lee, B. Y. (2019). Investigation of electronic-word-ofmouth on online social networking sites written by authors with commercial interest. Online Information Review, 43(3), 462-480.

Tankovic, A. C., \& Benazic, D. (2018). The perception of e-servicescape and its influence on perceived e-shopping value and customer loyalty. Online Information Review, 42(7), 1124-1145.

Teoh, W., Siong, M. Y., Chong, C., Lin, B., \& Chua, W., J (2013). Factors affecting consumers' perception of electronic payment: an empirical analysis. Internet Research, 23(4), 465-485.

Thackeray, R., Neiger, B. L., Hanson, C. L., \& McKenzie, J. F. (2008). Enhancing promotional strategies within social marketing programs: use of Web 2.0 social media. Health Promotion Practice, 9(4), 338343.

Trusov, M., Bucklin, R. E., \& Pauwels, K. (2009). Effects of word-ofmouth versus traditional marketing: findings from an internet social networking site. Journal of Marketing, 73(5), 90-102.

Tsai, J. Y., Egelman, S., Cranor, L., \& Acquisti, A. (2011). The effect of online privacy information on purchasing behavior: An experimental study. Information Systems Research, 22(2), 254-268.

Venkatesh, V., \& Bala, H. (2008). Technology acceptance model 3 and a research agenda on interventions. Decision Sciences, 39(2), 273 315 .

Venkatesh, V., \& Davis, F. D. (2000). A theoretical extension of the technology acceptance model: Four longitudinal field studies. Management Science, 46(2), 186-204.

Venkatesh, V., \& Speier, C. (1999). Computer technology training in the workplace: A longitudinal investigation of the effect of mood. Organizational Behaviour and Human Decision Processes, 79(1), $1-28$.
Venkatesh, V., Morris, M. G., Davis, G. B., \& Davis, F. D. (2003). User acceptance of information technology: Toward a unified view. MIS Quarterly, 425-478.

Venkatesh, V., Thong, J. Y., \& Xu, X. (2012). Consumer acceptance and use of information technology: extending the unified theory of acceptance and use of technology. MIS Quarterly, 36(1), 157-178.

Wang, Y. S., Wang, Y. M., Lin, H. H., \& Tang, T. I. (2003). Determinants of user acceptance of Internet banking: an empirical study. International Journal of Service Industry Management, 14(5), 501-519.

Wang, Z., Jin, Y., Liu, Y., Li, D., \& Zhang, B. (2018). Comparing social media data and survey data in assessing the attractiveness of Beijing Olympic Forest Park. Sustainability, 10(2), 382-400.

Weerakkody, V., Irani, Z., Kapoor, K., Sivarajah, U., \& Dwivedi, Y. K. (2017). Open data and its usability: an empirical view from the Citizen's perspective. Information Systems Frontiers, 19(2), 285 300.

Wixom, B. H., \& Todd, P. A. (2005). A theoretical integration of user satisfaction and technology acceptance. Information Systems Research, 16(1), 85-102.

Yang, K. C. (2005). Exploring factors affecting the adoption of mobile commerce in Singapore. Telematics and Informatics, 22(3), 257277.

Yousafzai, S. Y., Pallister, J. G., \& Foxall, G. R. (2003). A proposed model of e-trust for electronic banking. Technovation, 23(11), $847-860$.

Yu, H. C., Hsi, K. H., \& Kuo, P. J. (2002). Electronic payment systems: an analysis and comparison of types. Technology in Society, 24(3), $331-347$.

Zheng, X., Cheung, C. M., Lee, M. K., \& Liang, L. (2015). Building brand loyalty through user engagement in online brand communities in social networking sites. Information Technology \& People, 28(1), 90-106.

Zhou, T. (2011). Examining the critical success factors of mobile website adoption. Online Information Review, 35(4), 636-652.

Zhu, F. X., Wymer, W., \& Chen, I. (2002). IT-based services and service quality in consumer banking. International Journal of Service Industry Management, 13(1), 69-90.

Publisher's Note Springer Nature remains neutral with regard to jurisdictional claims in published maps and institutional affiliations. 